\title{
บUsisersily
}

\section{Central Composite Designed Formulation, Characterization and In-Vitro Cytotoxic effect of Erlotinib Loaded Chitosan Nanoparticulate System}

Pandey, P., Chellappan, D. K., Tambuwala, M. M., Bakshi, H., Dua, K., \& Dureja, H. (2019). Central Composite Designed Formulation, Characterization and In-Vitro Cytotoxic effect of Erlotinib Loaded Chitosan Nanoparticulate System. International Journal of Biological Macromolecules, 141, 596-610. https://doi.org/10.1016/j.ijbiomac.2019.09.023

Link to publication record in Ulster University Research Portal

\section{Published in:}

International Journal of Biological Macromolecules

Publication Status:

Published (in print/issue): 01/12/2019

DOI:

10.1016/j.ijbiomac.2019.09.023

\section{Document Version}

Version created as part of publication process; publisher's layout; not normally made publicly available

\section{General rights}

Copyright for the publications made accessible via Ulster University's Research Portal is retained by the author(s) and / or other copyright owners and it is a condition of accessing these publications that users recognise and abide by the legal requirements associated with these rights.

\section{Take down policy}

The Research Portal is Ulster University's institutional repository that provides access to Ulster's research outputs. Every effort has been made to ensure that content in the Research Portal does not infringe any person's rights, or applicable UK laws. If you discover content in the Research Portal that you believe breaches copyright or violates any law, please contact pure-support@ulster.ac.uk. 


\section{Journal Pre-proof}

Central composite designed formulation, characterization and in vitro cytotoxic effect of erlotinib loaded chitosan nanoparticulate system

Parijat Pandey, Dinesh Kumar Chellappan, Murtaza M. Tambuwala, Hamid A. Bakshi, Kamal Dua, Harish Dureja

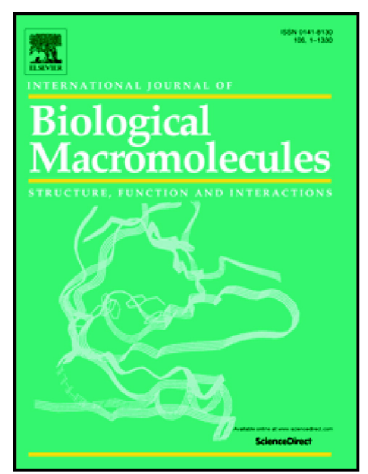

PII: $\quad$ S0141-8130(19)36374-3

DOI: $\quad$ https://doi.org/10.1016/j.ijbiomac.2019.09.023

Reference: $\quad$ BIOMAC 13268

To appear in: $\quad$ International Journal of Biological Macromolecules

Received date: $\quad 11$ August 2019

Revised date: $\quad 3$ September 2019

Accepted date: $\quad 4$ September 2019

Please cite this article as: P. Pandey, D.K. Chellappan, M.M. Tambuwala, et al., Central composite designed formulation, characterization and in vitro cytotoxic effect of erlotinib loaded chitosan nanoparticulate system, International Journal of Biological Macromolecules(2018), https://doi.org/10.1016/j.ijbiomac.2019.09.023

This is a PDF file of an article that has undergone enhancements after acceptance, such as the addition of a cover page and metadata, and formatting for readability, but it is not yet the definitive version of record. This version will undergo additional copyediting, typesetting and review before it is published in its final form, but we are providing this version to give early visibility of the article. Please note that, during the production process, errors may be discovered which could affect the content, and all legal disclaimers that apply to the journal pertain.

(C) 2018 Published by Elsevier. 
Central Composite Designed Formulation, Characterization and In-Vitro Cytotoxic effect of Erlotinib Loaded Chitosan Nanoparticulate System

Parijat Pandey ${ }^{\mathrm{a}}$, Dinesh Kumar Chellappan ${ }^{\mathrm{b}}$, Murtaza M Tambuwala ${ }^{\mathrm{c}}$, Hamid A Bakshi ${ }^{\mathrm{c}}$, Kamal Dua ${ }^{\mathrm{d}, \mathrm{e}, \mathrm{f}}$ and Harish Dureja ${ }^{\mathrm{g}_{*}}$

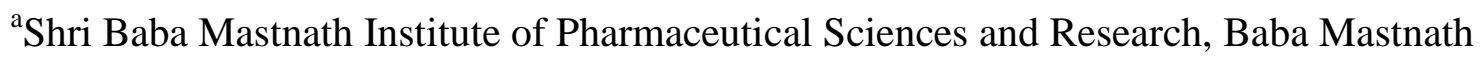
University, Rohtak - 124001, India

${ }^{\mathrm{b}}$ Department of Pharmaceutical Sciences, School of Pharmacy, International Medical University, Kuala Lumpur 57000, Malaysia

${ }^{\mathrm{c}}$ School of Pharmacy and Pharmaceutical Sciences, Ulster University, Coleraine, County, Londonderry, BT52 1SA, Northern Ireland, United Kingdom

${ }^{\mathrm{d}}$ Discipline of Pharmacy, Graduate School of Health, University of Technology, Sydney, 2007, Australia

${ }^{e}$ Priority Research Centre for Healthy Lungs, Hunter Medical Research Institute (HMRI) and School of Biomedical Sciences and Pharmacy, The University of Newcastle (UoN), Callaghan, NSW, 2308, Australia

${ }^{\mathrm{f}}$ Centre for Inflammation, Centenary Institute, Sydney, NSW 2050, Australia 2308, Australia

${ }^{\mathrm{g}}$ Department of Pharmaceutical Sciences, Maharshi Dayanand University, Rohtak - 124001, India

\footnotetext{
*Corresponding Author

Prof. Harish Dureja

Department of Pharmaceutical Sciences

Maharshi Dayanand University

Rohtak, India - 124001

E-mail - harishdureja@gmail.com

Mob - +91-9416357995
} 


\begin{abstract}
The most common cause of deaths due to cancers nowadays is lung cancer. The objective of this study was to prepare erlotinib loaded chitosan nanoparticles for their anticancer potential. To study the effect of formulation variables on prepared nanoparticles using central composite design. Erlotinib loaded chitosan nanoparticles were prepared by ionic gelation method using probe sonication technique. It was found that batch NP-7 has a maximum loading capacity and entrapment efficiency with a particle size $(138.5 \mathrm{~nm})$ which is ideal for targeting solid tumors. Analysis of variance was applied to the particle size, entrapment efficiency and percent cumulative drug release to study the fitting and the significance of the model. The batch NP-7 showed 91.57 percent and 39.78 percent drug release after $24 \mathrm{~h}$ in $0.1 \mathrm{~N}$ hydrochloric acid and Phosphate Buffer (PB) $\mathrm{pH}$ 6.8, respectively. The $\mathrm{IC}_{50}$ value of NP-7 evaluated on A549 Lung cancer cells was found to be $6.36 \mu \mathrm{M}$. The XRD of NP-7 displayed the existence of erlotinib in the amorphous pattern. The optimized batch released erlotinib slowly in comparison to the marketed tablet formulation. Erlotinib loaded chitosan nanoparticles were prepared successfully using sonication technique with suitable particle size, entrapment efficiency and drug release. The formulated nanoparticles can be utilized for the treatment of lung cancer.
\end{abstract}

Keywords: Erlotinib, ionic gelation, probe sonication. 


\section{Introduction}

Cancer is the second largest cause of death worldwide following cardiovascular diseases and the most common cause of deaths due to cancers includes lung cancer, both in women and men [1]. Among lung cancers, non-small cell lung cancer (NSCLC) is the most common form, with the major population of patients having advanced stage of the disease at the time of diagnosis [2]. According to the World Health Organization (WHO), cancer was found responsible for around 8.8 million deaths worldwide in 2015 among which, about 1.69 million deaths were associated with lung cancer only [3]. The number is expected to be increased around 19.3 million discovered cancer victims per annum by 2025. As per the World Cancer report of World Health Organization for the year 2017, approximately 9.6 million deaths were reported to be caused by cancer worldwide by the year 2018, and it is expected to reach the number of 22 million by the year 2035 [4].

Cancer nanotechnology is the most intriguing research area cutting across biology, chemistry, engineering, and medicine, aiming to develop advanced cancer therapies [4,5]. Nanotechnology has come as a new paradigm in the effective delivery of anticancer drugs. Advances in the design of nanoparticles (NPs) as drug delivery systems have provided huge opportunities in cancer targeted drug delivery and shown great promise in improving the therapeutic outcome of the already existing cancer therapies [6,7]. Owing to their small size, NPs have been endowed with unique characteristics; e.g., high surface area, easy surface modification, encapsulation of wide range of therapeutics, tunable properties, ligand conjugation and targeting capabilities $[8,9]$.

Depending on the method of preparation, polymeric nanoparticles can be formulated in the size range of 10-1000 nm. Polymeric systems have been used in cancer therapy since 1976, when a controlled release system was developed by Langer and Folkman for the delivery of macromolecules [10]. The drug may be either adsorbed on the surface of the nanoparticles or encapsulated into the polymer matrix. The latter is preferred as it protects the drug from the surrounding environment and provides controlled release capabilities; while adsorption is used for attaching the targeting ligands to the surface of the nanoparticles [11].

After screening a number of anticancer drugs, erlotinib was selected for the present study. Erlotinib got approval from USFDA under the trade name TARCEVA (Genetech, OSI 
Pharmaceuticals) for the treatment of two types of cancer including NSCLC and pancreatic cancer. Erlotinib falls in the novel class "targeted therapies", which is designed to inhibit the epidermal growth factor receptor (EGFR) [12]. These receptors generally do not occur in normal cells but found very commonly on the surfaces of a number of human tumor cells and constitute a group of four receptors i.e., ErbB-1 (EGFR), ErbB-2 (HER2/neu), ErbB-3 (HER3) and ErbB-4 (HER4) responsible for the continued existence of the cell [13]. When a ligand binds to EGFR, it leads to the phosphorylation of internal tyrosine kinase (TK) domain of the receptor and resulting into its activation, which further stimulates the several internal signaling pathways and thus affects proliferation, differentiation and cell survival. Evidence have suggested the role of this process in promoting the metastasis of cancer [14]. Erlotinib is a quinazolinamine derivative with the chemical name N-(3-ethynylphenyl)-6,7-bis(2-methoxyethoxy)-4-quinazolinamine [15]. Erlotinib hydrochloride is very slightly soluble in water and methanol and is practically insoluble in acetone, acetonitrile, hexane and ethyl acetate. The solubility in water depends on $\mathrm{pH}$ which increases at a $\mathrm{pH}<5$ as a result of the secondary amine's protonation. The solubility, nearly 0.4 $\mathrm{mg} / \mathrm{ml}$, is observed to be best at a $\mathrm{pH}$ value of 2 with a pKa value of 5.42 at $25^{\circ} \mathrm{C}[16,17]$. The chemical structure of Erlotinib is shown in Fig. 1.

For this study, Chitosan was selected as a polymer due to its biocompatibility, biodegradability, safety and its bioadhesive nature. Chitosan is the principal component of exoskeletons of marine crustaceans from which supplements are often derived. Chitosan is a natural polycationic copolymer which consists of glucosamine units and $\mathrm{N}$-acetyl glucosamine units. Chitosan is generally obtained by deacetylation of chitin derived from the exoskeleton of crustaceans [18].

The primary objective of the present work was to formulate the central composite designed erlotinib loaded chitosan nanoparticles using sonication technique. The main objective behind the work was to study the effect of three formulation variables i.e., the concentration of chitosan, the concentration of sodium tripolyphosphate (NaTPP) and sonication time on the particle size, drug entrapment and percent cumulative drug release of nanoparticles. Also, in the present study, authors used polyethylene glycol (PEG) as a surface stabilizer which helps to prevent the nanoparticles from opsonization and uptake by the reticuloendothelial system (RES) [19]. 


\section{Materials and method}

\subsection{Materials}

Erlotinib was obtained as a gift sample from Hetero Labs Limited, India. 95 percent deacetylated chitosan having a molecular weight around 40-80 kDa was procured from Fluka Chemika, Switzerland. Dimethyl Sulphoxide was purchased from Fisher Scientific Pvt. Ltd., India. Sodium tripolyphosphate (NaTPP), polyethylene glycol 600, glacial acetic acid, methanol and orthophosphoric acid were purchased from Loba Chemie Pvt. Ltd. India. The analytical grade was selected for all the other chemicals involved in the study, which were used as supplied by the manufacturer.

\subsection{Methods}

\subsubsection{Preparation of erlotinib loaded chitosan nanoparticles}

In this study, the NPs were synthesized using sonication technique as reported by Kumar et al., 2017 [20]. For this purpose, chitosan $(0.1-0.3$ percent w/v) was dissolved in glacial acetic acid $(0.2$ percent $\mathrm{v} / \mathrm{v})$. Double distilled water was used for the preparation of the solution of NaTPP $(0.2-0.3$ percent $\mathrm{w} / \mathrm{v})$. The drug solution was prepared separately by dissolving erlotinib (150 $\mathrm{mg}$ ) in methanol and dimethyl sulphoxide (1:1) and the surface stabilizers - PEG 600 (50 mg). During preliminary experimentation, the solubility studies of the drug was performed. It was observed that drug is highly soluble in methanol. The chitosan and drug solution were mixed together using magnetic stirrer at a speed of $1000-1200 \mathrm{rpm}$ for $4 \mathrm{~h}$ approximately. Then, NaTPP $(100 \mathrm{ml})$ was added dropwise at a rate of $1 \mathrm{drop} / \mathrm{s}$ while magnetic stirring. Then, this solution was sonicated using probe sonicator at $40^{\circ} \mathrm{C}$ at different time interval i.e. $14-20$ min; the obtained chitosan nanoparticle suspension was centrifuged at $26000 \mathrm{rpm}$ for $30 \mathrm{~min}$ at $16^{\circ} \mathrm{C}$. The supernatant was removed and chitosan nanoparticles were lyophilized using freeze-drying. The pictorial representation of the preparation of erlotinib loaded chitosan nanoparticles is shown in Fig. 2.

\subsubsection{Optimization of erlotinib loaded chitosan nanoparticles using central composite design}

Statistically designed experiments using central composite design (Design Expert@ Software (Version 11.0.4.0, Stat-Ease Inc., Minneapolis, MN) were performed for determining the effect of three critical variables - concentration of chitosan $\left(\mathrm{X}_{1}\right)$, concentration of NaTPP $\left(\mathrm{X}_{2}\right)$ and 
sonication time $\left(\mathrm{X}_{3}\right)$ on the particle size, entrapment efficiency and percent cumulative drug release in $0.1 \mathrm{~N}$ hydrochloric acid and Phosphate Buffer (PB) $\mathrm{pH}$ 6.8. The central composite design (CCD) constituting $6(2 \mathrm{n})$ batches on axial points (1S-6S), $8\left(\mathrm{k}_{\mathrm{n}}\right)$ batches of full factorial design $(1 \mathrm{~F}-8 \mathrm{~F})$ and 4 replicates at the centre points $(1 \mathrm{C}-4 \mathrm{C})$. The eighteen batches of erlotinib loaded chitosan nanoparticles (NP-1 to NP-18) are enlisted in Table 1. For nonlinear responses requiring second order models, CCDs are most frequently employed. The composite design contains an imbedded $\left(2^{\mathrm{k}}\right) \mathrm{FD}$ or $\left(2^{\mathrm{k}-\mathrm{r}}\right) \mathrm{FFD}$, augmented with group of star points (2k) and a central point. The total number of factor combinations in a CCD is $2^{\mathrm{k}}+2 \mathrm{k}+1$.

\section{Characterization of erlotinib loaded chitosan nanoparticles}

\subsection{Particle size, polydispersity index (PDI) and zeta potential}

For particle size and zeta potential analysis, the dilution of sample was analyzed by dissolving the sample $(2 \mathrm{mg})$ in distilled water $(5 \mathrm{ml})$ using Zetasizer nano series Nano-ZS90 (Malvern Instruments, Malvern, UK) which is equipped with the Hydro dispersing unit. Dilution of the sample was filled in a cuvette made up of polystyrene in hydro dispensing unit and then scan was carried out at a rate of 64 runs per sample. As the scan is completed, the average diameter per scan was taken out and recorded as Z-average for all the 64 runs [21-24].

\subsection{Loading capacity, entrapment efficiency and percentage yield}

The loading capacity, entrapment efficiency and percentage yield were determined directly using erlotinib loaded chitosan nanoparticles by analysis of the samples in suspension after centrifugation in sonication technique. The extracted erlotinib in the supernatant after ultracentrifugation of the nanoparticles suspension was determined using the high-performance liquid chromatography (HPLC) method. The HPLC analyses were carried out using a system (Agilent technologies 1200 series, Germany) that consisted reverse phase $\mathrm{C}_{18}$ column $(25 \mathrm{~cm} \times$ $4.6 \mathrm{~mm} \times 5 \mu \mathrm{m}$ ) with mobile phase consisting of 0.1 percent orthophosphoric acid and methanol $(70: 30 \mathrm{v} / \mathrm{v})$ was used. The flow rate was $1.0 \mathrm{ml} \mathrm{min}^{-1}$ and the effluents were monitored at 247 $\mathrm{nm}$. Each sample was assayed in triplicate. The loading capacity, entrapment efficiency, and percentage yield were calculated according to the following equations [25];

$$
\text { Loading Capacity (percent) }=\frac{\text { Total drug }- \text { Free drug }}{\text { Nanoparticles weight }} \times 100
$$




$$
\text { Entrapment Efficiency (percent) } \quad=\quad \frac{\text { Total drug }- \text { Free drug }}{\text { Total drug }} \times 100
$$

$$
\text { Percentage Yield (percent) } \quad=\quad \frac{\text { Total nanoparticles weight }}{\text { Total solid weight }} \times 100
$$

\subsection{In vitro release study}

In vitro drug release of erlotinib loaded chitosan nanoparticles was assessed by dialysis bag diffusion technique (specification: Av. Diameter-21.5 mm, Av. Flat width-32.34 mm, Capacity$3.63 \mathrm{ml} / \mathrm{cm}^{2}$ ) in $0.1 \mathrm{~N}$ hydrochloric acid and $\mathrm{PB} \mathrm{pH}$ 6.8. The prepared erlotinib loaded chitosan nanoparticles (weight equivalent to $150 \mathrm{mg}$ of drug) were transferred to a cellulose dialysis bag (molecular weight cut-off 12000 Da; Himedia, Mumbai, India) which sealed from both ends. The dialysis bag was immersed in the cylindrical vessel of USP dissolution apparatus II (Lab India DS 8000, Mumbai, India) containing $200 \mathrm{ml}$ of dissolution medium maintained at a temperature of $37^{\circ} \mathrm{C} \pm 0.5^{\circ} \mathrm{C}$. The rotating speed was set at $75 \mathrm{rpm}$. After certain time intervals in hours $(0.5$, $1,2,4,6,8,12,18,24)$, the aliquots of $2 \mathrm{ml}$ were taken out from the release media at different time intervals and were replaced with the same volume of fresh receptor medium. The samples were analyzed by HPLC technique. All the experiments were performed in triplicate and the average values were assessed [26].

\subsection{Drug release kinetic study}

The in vitro drug release data of the optimized erlotinib loaded chitosan nanoparticles were fitted to various kinectics equations such as zero order, first order, higuchi model and Korsmeyerpeppas model. The correlation coefficient $\left(\mathrm{R}^{2}\right)$ values were obtained for determining the mechanism and kinetics of drug release. In order to understand the mechanism and kinetics of drug release from tablets, the in vitro drug release study data was fitted into various kinetics equations [27].

\subsection{Differential scanning calorimetry (DSC) analysis}

DSC measurements were carried out on DSC Q10 V9.9, TA Instruments, Waters, USA. Calibration of the instrument was done by using indium as standard. Samples were placed in 
sealed aluminium pans and heated from $30^{\circ} \mathrm{C}$ to $300^{\circ} \mathrm{C}$ at a rate of $10^{\circ} \mathrm{C} / \mathrm{min}$ under an atmosphere of nitrogen $(60 \mathrm{ml} / \mathrm{min})$, taking an empty pan as a reference [28].

\subsection{Attenuated total reflectance (ATR)}

ATR spectrum was recorded on ATR Alpha, Bruker, Germany. The spectrum was recorded over the range of $500-3500 \mathrm{~cm}^{-1}$ [29].

\subsection{X-ray diffraction (XRD) analysis}

The sample is installed on the instrument by holding it in place with one hand and with the other, press the stage up button until it locks. The slits in the 'anti-scattering' and 'detector' positions are verified as per the requirement of the procedure. The doors then slide together carefully and gently to interlock. After closing the doors, 'XRD commander' is expanded in the computer and power is raised if necessary. The scan is taken and auto-saved. When the task is finished sample is removed and enclosure doors are closed. The XRD spectra of the pure drug erlotinib and optimized batch formulation were recorded at room temperature using $\mathrm{x}$-ray diffractometer (XRD-D 8 Focus, Bruker, Germany) with a voltage of $40 \mathrm{kV}, 40 \mathrm{~mA}$ current [30].

\subsection{Transmission electron microscopy (TEM)}

The morphology and surface-appearance of nanoparticles were observed via FEI Company Tecnai TF20 high resolution Transmission Electron Microscope, Hillsboro, Oregon, USA. The TEM facility consists of a $200 \mathrm{KV}$ TEM, equipped with a high brightness field-emission gun source which produces improved sensitivity and resolution compared to more traditional thermionic sources like LaB6 or Tungsten filaments. TEM is equipped with a $4 \mathrm{~K} \times 4 \mathrm{~K}$ Eagle Charged Coupled Device camera with a 4-port readout. $5 \mu \mathrm{L}$ sample was placed onto the carbon film-coated copper grid (300 mesh size) and allowed to settle down for $2 \mathrm{~min}$. The excess of the sample was wiped out with tissue paper. The sample loaded grid was stained with $5 \mu \mathrm{L}$ of 2 percent uranyl acetate (negative stain) and allowed to settle down for $2 \mathrm{~min}$. The excess stain was wiped out with tissue paper. Grid was allowed to dry for $3 \mathrm{~h}$ and visualized [31].

\subsection{Cytotoxicity study}

\subsubsection{Cell culture and treatment}

The A549 Lung cancer cells were procured and grown in DMEM media containing FBS (10 percent), penicillin (100 units $/ \mathrm{ml})$ and streptomycin $(100 \mu \mathrm{g} / \mathrm{ml})$. The cells were maintained at 
$37^{\circ} \mathrm{C}$ in a 5 percent $\mathrm{CO}_{2}$ humidified incubator. After the cell became confluent, the culture media was removed and washed with 1 percent PBS solution to inactivate the existing media in culture. After that, treatment with trypsin-EDTA 0.25 percent (w/v) solution was given for trypsinization. Subsequently trypsin was inactivated by adding DMEM media, cells were collected and centrifuged at $1200 \mathrm{rpm}$ at $37^{\circ} \mathrm{C}$ for $5 \mathrm{~min}$. The maintenance of cultured cell line was done in 25 $\mathrm{cm}^{2}$ flask [32]. The same steps were repeated for maintaining the cells [33].

\subsubsection{3-(4,5-dimethythiazol-2-yl)-2,5-diphenyl tetrazolium bromide (MTT) assay}

MTT assay was performed for evaluating the anti-proliferative potential of the compounds under investigation. 96-well plate method was used for carrying out this assay in which each well was filled with $100 \mu \mathrm{l}$ complete media. Treatment was given as two concentrations viz., 1 , and $5 \mu \mathrm{M}$ and the cells were then incubated for $24 \mathrm{~h}$. After $24 \mathrm{~h}$, media was discarded with subsequent washing using 1X PBS and further treatment with MTT dye (5 mg in $10 \mathrm{~mL}$ of $1 \mathrm{X}$ PBS) and incubated again at room temperature thereafter in dark for $4 \mathrm{~h}$ to allow the formation of formazan crystals. The crystals were dissolved in dimethyl sulphoxide and resulting absorbance was spectrometrically read using microplate reader at $570 \mathrm{~nm}$. The result was established in triplicate $[32,33]$.

\subsection{Stability studies}

For the development of a pharmaceutically satisfactory product, stability study is the most important evaluation parameter. Stability regarding any dosage form stands for its possible way to persist within the physical, chemical, toxicological and therapeutic specification. In the present study, the stability studies of optimized nanoparticle formulation were carried out after storing the formulation at freeze temperature $\left(4^{\circ} \mathrm{C} \pm 1^{\circ} \mathrm{C}\right)$, room temperature $\left(25^{\circ} \mathrm{C} \pm 2^{\circ} \mathrm{C} / 60\right.$ percent \pm 5 percent $\mathrm{RH})$ and $\left(45^{\circ} \mathrm{C} \pm 2^{\circ} \mathrm{C} / 75\right.$ percent \pm 5 percent $\left.\mathrm{RH}\right)$ as per $\mathrm{ICH}$ guidelines. The optimized formulations were evaluated for various parameters such as particle size and percent cumulative drug release after 1,2,3 and 6 months.

\subsection{Comparison of in vitro diffusion profile with marketed formulation}

The optimized erlotinib loaded chitosan nanoparticles were compared with the marketed formulation of erlotinib (Erlocip-150, Cipla, India) for in vitro drug release. A model 
independent approach was used employing a difference factor $\left(f_{1}\right)$ and similarity factor $\left(f_{2}\right)$ as given in Eq 4 and 5, respectively [34].

$$
\begin{aligned}
& f_{1}=\frac{\sum\left[R_{t}-T_{t}\right]}{\sum^{R_{t}}} \times 100 \\
& f_{2}=\left\lfloor 50 . \log \frac{1}{\left.\sqrt{1+\frac{1}{n} \Sigma^{\left(R_{t}-T_{t}\right)^{2}}}\right\rfloor \times 100}\right.
\end{aligned}
$$

where, $R_{t}=$ percent released for reference (marketed formulation)

$\mathrm{T}_{\mathrm{t}}=$ percent released for test formulation (NP-7) at different time point

$\mathrm{n}=$ the number of time points in release profile.

The time intervals used for determining the $f_{1}$ and $f_{2}$ values in this study were up to $24 \mathrm{~h}$. The profiles of two drugs or formulations are considered similar if the values of $f_{1}$ and $f_{2}$ lies between 0-15 and between 50-100, respectively. If the value comes less than 50, it indicates the release profiles of two drugs are different [35].

\section{Results and Discussion}

A total 18 formulations of erlotinib loaded chitosan nanoparticles were prepared using central composite design for optimizing three factors - concentration of chitosan $\left(\mathrm{X}_{1}\right)$, the concentration of NaTPP $\left(\mathrm{X}_{2}\right)$ and sonication time $\left(\mathrm{X}_{3}\right)$ at two levels. All batches were analyzed to determine their particle size, polydispersity index, zeta potential, loading capacity, entrapment efficiency and percentage yield (Table 2). The results demonstrated that batch NP-7 prepared with a low concentration of chitosan, high concentration of NaTPP and high value of sonication time had shown highest loading capacity $(77.15 \pm 0.15$ percent $)$ and entrapment efficiency $(49.02 \pm 0.24$ percent) with particle size (138.5 nm) (Fig. 3a) having polydispersity index (PDI) value 0.382. The value of PDI > 0.7 reveals very wide particle size distribution i.e., the highly polydisperse system. The value of PDI $<0.5$ reveals highly monodisperse system. The polydisperse system has a greater tendency to aggregate than the monodisperse system [36].

The high loading capacity may be resulted due to the behaviour of a drug and chitosan in the solution. The cross-linking agent NaTPP also forms additional hydrogen bonds with the drug and chitosan leading to more compact nanoparticles which was confirmed by the ATR analysis. The hydrogen bonds between chitosan and drug were also concluded based on an earlier report [37]. 
The affinity of TPP for the drug was increased by using surface stabilizer PEG 600 which consequently increased the drug loading. To assist the orthogonality of results and easy calculations, the real values of factors were transformed. The extent of contribution of different factors towards particle size, entrapment efficiency and in vitro drug release was determined by performing multiple linear regression analysis using Design Expert Software version 11.0.4.0.

The effect of various parameters on different responses was determined using the polynomial equation, pareto plot, 3D response surface plot and contour plot constructed using Design Expert ${ }^{\circledR}$ software. A significant effect was determined to find percentage variability in different responses obtained and a probability value of $\mathrm{P}<0.05$ was considered as significant level. Analysis of Variance was applied to all the response obtained to study the significance of the model.

The polynomial equation for particle size is as follows:

Particle Size $=+446.15+88.02 \mathrm{X}_{1}-34.55 \mathrm{X}_{2}+157.61 \mathrm{X}_{3}+62.75 \mathrm{X}_{1} \mathrm{X}_{2}+52.03 \mathrm{X}_{1} \mathrm{X}_{3}-14.15$ $\mathrm{X}_{2} \mathrm{X}_{3}+6.34 \mathrm{X}_{1}^{2}-66.40 \mathrm{X}_{2}^{2}-28.44 \mathrm{X}_{3}^{2}$

The coefficient estimates the value of the concentration of chitosan $\left(\mathrm{X}_{1}\right)$ and sonication time $\left(\mathrm{X}_{3}\right)$ were found to be positive indicating that the increase in the concentration of chitosan and sonication time lead to an escalation in particle size whereas the concentration of $\operatorname{NaTPP}\left(\mathrm{X}_{2}\right)$ was found to be negative. The effects of various coefficients on particle size are shown in Fig. $3(b)$.

The quadratic model was found to be significant $(p=0.0289)$ with an $F$-value of 4.14 for particle size. The effect of main and interactive variables on the response was also determined. The $p$ value of $\mathrm{X}_{1}$ was found to be 0.0314 and 0.3366 , respectively, whereas the $p$-value for $\mathrm{X}_{3}$ was found to be 0.0016 . In this case, $X_{1}$ and $X_{3}$ were significant model terms.

The effect of different process variables on the response of particle size is also determined with the help of 3D response surface plot and contour plot as shown in Fig. 3(c) and 3(d), respectively. Analysis of Variance was applied to the responses obtained to assess the fitting and significance of model as shown in Table 3.

The polynomial equation for entrapment efficiency is as follows: 
Entrapment Efficiency $=+71.84-3.20 \mathrm{X}_{1}+0.61 \mathrm{X}_{2}+2.06 \mathrm{X}_{3}+0.15 \mathrm{X}_{1} \mathrm{X}_{2}-0.41 \mathrm{X}_{1} \mathrm{X}_{3}+0.42$ $\mathrm{X}_{2} \mathrm{X}_{3}-1.86 \mathrm{X}_{1}^{2}-0.53 \mathrm{X}_{2}^{2}-0.68 \mathrm{X}_{3}^{2}$

The coefficient estimates the value of concentration of chitosan $\left(\mathrm{X}_{1}\right)$ was found to be negative indicated that entrapment efficiency increases with respect to the decrease in the corresponding variable whereas concentration of $\operatorname{NaTPP}\left(\mathrm{X}_{2}\right)$ and sonication time $\left(\mathrm{X}_{3}\right)$ were found to be positive showed that entrapment efficiency increases with respect to the increase in the corresponding variables. The effects of various coefficients for entrapment efficiency are shown in Fig. 4(a).

The quadratic model was found to be significant $(p=0.0022)$ with an $F$-value of 9.41 for entrapment efficiency. The $p$-value of $\mathrm{X}_{1}$ and $\mathrm{X}_{2}$ were found to be 0.0002 and 0.2208 , respectively, whereas the $p$-value for $\mathrm{X}_{3}$ was found to be 0.0022 . In this case, $\mathrm{X}_{1}, \mathrm{X}_{3}$ and $\mathrm{X}_{1}{ }^{2}$ were significant model terms.

The effect of different process variables on the response of entrapment efficiency is determined with the help of 3D response surface plot and contour plot as shown in Fig. 4(b) and 4(c), respectively. Analysis of Variance was applied to the response obtained for studying the fitting and significance of the model (Table 3).

The polynomial equation for percent cumulative drug release in $0.1 \mathrm{~N}$ hydrochloric acid is as follows:

Percent Cumulative Drug Release $=+76.95-1.22 \mathrm{X}_{1}+1.01 \mathrm{X}_{2}+0.68 \mathrm{X}_{3}-0.52 \mathrm{X}_{1} \mathrm{X}_{2}+0.29 \mathrm{X}_{1} \mathrm{X}_{3}$ $+0.34 \mathrm{X}_{2} \mathrm{X}_{3}+1.73 \mathrm{X}_{1}^{2}+2.25 \mathrm{X}_{2}^{2}+4.17 \mathrm{X}_{3}^{2}$

The coefficient estimates value of concentration of chitosan $\left(X_{1}\right)$ was found to be negative, which indicates that percent cumulative drug release increases with respect to the decrease in the corresponding variable whereas concentration of NaTPP $\left(\mathrm{X}_{2}\right)$, sonication time $\left(\mathrm{X}_{3}\right)$ which indicates that percent cumulative drug release increases with respect to the increase in the corresponding variable. The effects of various coefficients on percent cumulative drug release are shown in Fig. 5(a).

The quadratic model was found to be significant $(p=0.0408)$ with an $F$-value of 3.65 for percent cumulative drug release in $0.1 \mathrm{~N}$ hydrochloric acid. The $p$-value of $\mathrm{X}_{1}$ and $\mathrm{X}_{2}$ were found to be 
0.0169 and 0.2492 , respectively, whereas the $p$-value for $X_{3}$ was found to be 0.4202 . In this case, $\mathrm{X}_{1}, \mathrm{X}_{2}^{2}$ and $\mathrm{X}_{3}^{2}$ were significant model terms.

The effect of different process variables on the response of percent cumulative drug release is determined with the help of 3D response surface plot and contour plot as shown in Fig. 5(b) and 5(c), respectively. Analysis of Variance was applied on the response obtained for evaluating the fitting and significance of model (Table 3).

The polynomial equation for percent cumulative drug release in $\mathrm{PB}$ pH 6.8 is as follows: percent Cumulative Drug Release $=+23.35-0.91 \mathrm{X}_{1}+1.05 \mathrm{X}_{2}+0.76 \mathrm{X}_{3}-0.43 \mathrm{X}_{1} \mathrm{X}_{2}+0.79 \mathrm{X}_{1} \mathrm{X}_{3}$ $-0.10 \mathrm{X}_{2} \mathrm{X}_{3}+3.29 \mathrm{X}_{1}^{2}+2.59 \mathrm{X}_{2}^{2}+5.38 \mathrm{X}_{3}^{2}$

The coefficient estimates value of concentration of chitosan $\left(\mathrm{X}_{1}\right)$ was found to be negative which indicates that percent cumulative drug release increases with respect to the decrease in the corresponding variable whereas concentration of $\operatorname{NaTPP}\left(\mathrm{X}_{2}\right)$, sonication time $\left(\mathrm{X}_{3}\right)$ were found to be positive which indicates that percent cumulative drug release increases with respect to the increase in the corresponding variable. The effects of various coefficients on percent cumulative drug release in shown in Fig. 6(a).

The quadratic model was found to be significant $(p=0.0264)$ with an $F$-value of 4.27 for percent cumulative drug release in $\mathrm{PB} \mathrm{pH}$ 6.8. The $p$-value of $\mathrm{X}_{1}$ and $\mathrm{X}_{2}$ were found to be 0.3696 and 0.3084 , respectively, whereas the $p$-value for $\mathrm{X}_{3}$ was found to be 0.4471 . In this case, $\mathrm{X}_{1}{ }^{2}, \mathrm{X}_{2}{ }^{2}$ and $\mathrm{X}_{3}^{2}$ were significant model terms.

The effect of different process variables on the response of percent cumulative drug release is also determined with the help of 3D response surface plot and contour plot as shown in Fig. 6(b) and 6(c), respectively. Analysis of Variance was applied to the response obtained to study the fitting and significance of the model (Table 3).

\subsection{In vitro release studies}

In vitro drug release of central composite designed erlotinib loaded chitosan nanoparticles using sonication technique was evaluated using $0.1 \mathrm{~N}$ hydrochloric acid and $\mathrm{PB} \mathrm{pH} 6.8$ by dialysis bag diffusion technique [20]. The in vitro release study of erlotinib was investigated in two different media i.e. $0.1 \mathrm{~N}$ hydrochloric acid and $\mathrm{PB}$ pH 6.8 to analyze the amount of drug released in acidic 
environment as well as in simulated intestinal fluid. The cumulative drug release of all the batches in $0.1 \mathrm{~N}$ hydrochloric acid ranged from 76.81 percent to 91.57 percent after $24 \mathrm{~h}$. Out of all the formulations, NP-7 containing the low value of chitosan, the high value of NaTPP and high value of sonication time had shown maximum release i.e. 91.57 percent of erlotinib loaded chitosan nanoparticles in $0.1 \mathrm{~N}$ hydrochloric acid after $24 \mathrm{~h}$. Cumulative drug release for all the central composite designed erlotinib loaded chitosan nanoparticles in $\mathrm{PB}$ pH 6.8 ranged from 23.10 percent to 39.78 percent after $24 \mathrm{~h}$. The higher percent CDR was found in an acidic buffer in comparison to basic buffer as erlotinib is a free base and is more susceptible to dissolve in the acidic solution. Out of all the formulations, NP-7 had shown maximum release i.e. 39.78 percent of erlotinib loaded chitosan nanoparticles in PB pH 6.8 after $24 \mathrm{~h}$. The release rate of erlotinib from chitosan nanoparticles exhibited a sustained release profile in the $0.1 \mathrm{~N}$ hydrochloric acid and $\mathrm{PB}$ pH 6.8 and the release rate of erlotinib was highest in the simulated gastric fluid medium after $24 \mathrm{~h}$. The sustained release manner of the central composite designed erlotinib loaded chitosan nanoparticles may extend the time of absorption of the drug in the gastrointestinal tract, which might be helpful to enhance the therapeutic activity of the drug and to reduce the side effects. The reason for carrying out the in vitro release study of Erlotinib in two different media i.e. $0.1 \mathrm{~N}$ hydrochloric acid and $\mathrm{PB} \mathrm{pH} 6.8$ was to confirm the release of Erlotinib in both the basic as well as in the acidic environment. Although the drug solubilizes in both the media, it dissolves faster in acidic medium.

\subsection{Release kinetics}

Among all the models applied in the study, Higuchi model showed the highest value of $\mathrm{R}^{2}$ for invitro release data for NP-7 obtained in the $0.1 \mathrm{~N}$ hydrochloric acid (0.999) and PB pH 6.8 (0.991). In this study, the value of $\mathrm{n}$ in Korsmeyer-Peppas model for in vitro release data in $0.1 \mathrm{~N}$ hydrochloric acid and PB pH 6.8 was found to be 0.689 and 0.929 , respectively which suggested that the mechanism for release followed by the erlotinib loaded chitosan nanoparticles using sonication technique is non-fickian anomalous diffusion, suggesting that the drug release is controlled by all the mechanisms including erosion, diffusion and swelling. But the highest $\mathrm{R}^{2}$ value for the Higuchi model showed the release mechanism followed primarily is diffusion in comparison to erosion and swelling. The results recommended that the erlotinib hydrochloride release from the formulated nanoparticles occurred mainly by the diffusion mechanism i.e. the 
dissolution medium permeates into the polymeric matrix of erlotinib nanoparticles, slowly dissolves the erlotinib and drug is released to the dissolution medium by diffusion mechanism.

\subsection{Differential scanning calorimetry}

The disappearance of endothermic peak of the optimized batch NP-7 including all the batches of central composite designed erlotinib loaded chitosan nanoparticles using sonication technique showed that drug may have been dispersed or dissolved in the polymer matrix during the formation of nanoparticles. The total incorporation of the drug into the nanoparticles suggested a molecular dispersion of drug inside the system. The nano-entrapment process produced a marked decrease in crystallinity of erlotinib and allows a nearly amorphous state [25]. The DSC thermogram of erlotinib, chitosan and optimized batch NP-7 are shown as an overlay in Fig. 7(a). The overlay of DSC thermograms of central composite designed erlotinib loaded chitosan nanoparticles of NP-1 to NP-6, NP-7 to NP-12 and NP-13 to NP-18 are shown in Fig. 7(b)-7(d), respectively.

\subsection{Attenuated total reflectance}

The ATR spectrum of erlotinib hydrochloride, chitosan and the optimized batch NP-7 are shown as overlay in Fig. 8(a). There was no significant difference in the ATR spectra of erlotinib hydrochloride and all the batches of central composite designed erlotinib loaded chitosan nanoparticles using sonication technique. On comparing the obtained spectra with the reference spectra, no overlapping of characteristic peaks, no significant shifting of functional peaks, and also no new peaks were observed in case of optimized batch NP-7. The results suggested that the drug was stable during the process of entrapment. The ATR data also suggested that there was no molecular interaction and no chemical interaction between functional groups of the polymer and drug occurred during the process [38]. The overlay of ATR of central composite designed erlotinib loaded chitosan nanoparticles of NP-1 to NP-6, NP-7 to NP-12 and NP-13 to NP-18 are shown in Fig. 8(b)-8(d), respectively.

\subsection{XRD analysis}

Powder X-ray diffraction pattern of pure drug erlotinib hydrochloride and chitosan are shown in Fig. 9(a) and 9 (b), respectively. The $2 \theta$ value of erlotinib at $38.04^{\circ}, 27.86^{\circ}, 27.84^{\circ}, 27.78^{\circ}$, $26.64^{\circ}, 25.92^{\circ}, 24.88^{\circ}, 22.94^{\circ}, 20.74^{\circ}, 18.26^{\circ}, 17.32^{\circ}$ and $15.12^{\circ}$ strongly indicated crystalline 
nature of erlotinib hydrochloride. The x-ray diffraction of optimized batch NP-7 displayed the existence of erlotinib hydrochloride in amorphous pattern as shown in Fig. 9(c).

\subsection{Transmission electron microscopy}

The TEM image of the optimized batch of central composite designed erlotinib loaded chitosan nanoparticle NP-7 is shown in Fig. 10. The optimized batch NP-7 was found to be spherical in shape. TEM was used at the nanoscale with magnification $25 \mathrm{k}$.

\subsection{Stability studies}

The optimized batch NP-7 was subjected to stability studies. The formulation NP-7 was found stable after six-month study as no considerable transformation was detected in the above parameters as shown in Table 4. The size of the NP-7 increased with the rise in time intervals due to the aggregation of the particles. The increase in particle size of NP-7 formulation was found to be least at $4{ }^{\circ} \mathrm{C}$ as compared with the formulation stored at room temperature and $45^{\circ} \mathrm{C}$ for six-months. The percent cumulative drug release (0.1N hydrochloric acid and $\mathrm{PB} \mathrm{pH} 6.8)$ decreased after storage. At $45^{\circ} \mathrm{C}$, the maximum fall in percent cumulative drug release of optimized batch NP-7 was seen as compared with the formulation stored at room temperature and $4{ }^{\circ} \mathrm{C}$ for six months. From the results, it can be concluded that for better stability, the formulation should be stored at $4^{\circ} \mathrm{C}$.

\subsection{Comparison with marketed formulation}

The optimized batch NP-7 showed 10.86 percent and 2.56 percent of drug release in $0.1 \mathrm{~N}$ hydrochloric acid and PB pH 6.8 within 1 h, respectively whereas the marketed tablet released $81.46 \pm 0.23$ percent and $26.78 \pm 0.12$ percent in $0.1 \mathrm{~N}$ hydrochloric acid and $\mathrm{PB} \mathrm{pH} 6.8$ within $1 \mathrm{~h}$, respectively. After $24 \mathrm{~h}$, the optimized batch showed 91.57 percent and 39.78 percent of drug release in $0.1 \mathrm{~N}$ hydrochloric acid and $\mathrm{PB} \mathrm{pH} 6.8$, respectively, whereas the marketed tablet released 95.76 percent and 44.54 percent in $0.1 \mathrm{~N}$ hydrochloric acid and $\mathrm{PB} \mathrm{pH} 6.8$ within $24 \mathrm{~h}$, respectively (Table 5). The optimized nanoparticle formulation NP-7 released erlotinib slowly in comparison to marketed tablet formulation which may help in improving the therapeutic efficacy of the drug and reducing the side effects of conventional tablet dosage form [39].

\subsection{Comparison of in vitro diffusion profiles}


In the present study, in vitro release was found to be slow for optimized nanoparticle formulations (NP-7) in comparison to the available tablet formulation in the market. The cumulative amount of drug release for NP-7 at $24 \mathrm{~h}$ was found to be $39.78 \pm 0.78$ percent and for Erlocip tablets, it was observed to be $44.54 \pm 0.42$. The slow drug release from the optimized formulations may be attributed to the property of nanoformulation of making the drug slowly available for release and hence the synthesized nanoparticles of erlotinib hydrochloride showed slow in vitro drug release than the available marketed formulation. The $f_{1}$ and $f_{2}$ values for the NP-7 as compared to that of the marketed Erlocip-150 tablets, when calculated using the equation at $24 \mathrm{hrs}$ were found to be 51.06 and 14.28 , respectively.

\subsection{Cytotoxic studies}

Cytotoxic activity of the pure drug erlotinib hydrochloride and central composite designed erlotinib loaded chitosan nanoparticles using sonication technique (NP-7 and NP-13) were studied. The reason for selecting two batches for cytotoxicity studies were to compare the batch having the minimum particle size (NP-13) and other batch (NP-7) having the maximum loading capacity and entrapment efficiency. The batch NP-7 and NP-13 showed the maximum inhibition of lung cancer (A549) cells. Among both the batches, NP-13 had shown more cytotoxicity in comparison to NP-7 because the NP-13 had less particle size and more zeta potential value. It has been reported that the drug uptake in cancer cells is highly dependent on the particle size and higher value of positive zeta potential facilitate cytotoxicity in cancer cells due to stronger interaction with the tumor cell membrane. Free erlotinib hydrochloride had shown more cytotoxicity than the erlotinib loaded chitosan nanoparticles (NP-7 and NP-13). The less cytotoxicity of erlotinib loaded chitosan nanoparticles might be due to the slow release rate of erlotinib loaded chitosan nanoparticles (NP-7 and NP-13) [40]. The $\mathrm{IC}_{50}$ value of free erlotinib was $1.03 \mu \mathrm{M}$ while the $\mathrm{IC}_{50}$ value of NP-7 and NP-13 were $6.36 \mu \mathrm{M}$ and $5.95 \mu \mathrm{M}$, respectively. In this study, the cytotoxicity of the central composite designed erlotinib loaded chitosan nanoparticles might be associated with the particle size and zeta potential. The $\mathrm{IC}_{50}$ values of the pure drug erlotinib hydrochloride and the nanoparticle formulation (NP-7 and NP-13) are shown in Table 6.

\section{Conclusion}


The formulation of nanoparticles by ionic-gelation method utilizing sonication technique was found to be an effective and simple method in which the particle size and distribution of the drug can be monitored by varying the variables like the concentration of chitosan, the concentration of NaTPP and sonication time. Erlotinib loaded chitosan nanoparticles were successfully prepared by applying CCD with effective use of surface stabilizing agent PEG 600. The optimized nanoparticles were obtained with a particle size range which can be effective in prolonging the circulation time of the drug helping in the delivery of the drug at the target site. The mathematical developed models can be used further for the formulation of nanoparticles with the desired characteristics. The $f_{1}$ value higher than 15 and $f_{2}$ lower than 50 indicated differences in the in vitro release profiles of the prepared and optimized nano-formulations and the marketed Erlotinib hydrochloride tablet (Erlocip-150). The formulated nanoparticles showed non-fickian mechanism for diffusion indicating that the release of drug is controlled by all diffusion, erosion and swelling mechanisms. The nanoparticle showed the maximum cytotoxic effect on A549 cancer cell line. The stability studies concluded that the nanoparticle formulations should be stored at $4^{\circ} \mathrm{C}$. The optimized nanoparticle formulation released erlotinib slowly in comparison to marketed tablet formulation which may help in improving the therapeutic efficacy of the drug and reducing the side effects of the existing conventional tablet dosage form.

\section{Conflict of Interest}

The authors confirm that this article content has no conflict of interest.

\section{Acknowledgement}

Declared none.

\section{Human and Animal Rights}

No human or animal studies were carried out by the authors for this article.

\section{References}

[1] Cancer Key Facts, http://www.who.int/news-room/fact-sheets/detail/cancer, Accessed 20 February 2018.

[2] W. Li, S. Ren, J. Li, A. Li, L. Fan, X. Li, C. Zhao, Y. He, G. Gao, X. Chen, S. Li, J. Shi, C. Zhou, K. Fei, G. Schmid-Bindert, T790M mutation is associated with better efficacy of 
treatment beyond progression with EGFR-TKI in advanced NSCLC patients, Lung Cancer 84 (3), 2014, 295-300.

[3] Key statistics for lung cancer, https://www.cancer.org/cancer/non-small-cell-lungcancer/about/key-statistics.html, 2018, Accessed 22 April 2019.

[4] Key statistics for cancer, http://www.who.int/news-room/fact-sheets/detail/cancer, 2018, Accessed 30 September 2018.

[5] P. Sharma, M. Mehta, D.S. Dhanjal, S. Kaur, G. Gupta, H. Singh, L. Thangavelu, S. Rajeshkumar, M. Tambuwala, H.A. Bakshi, D.K. Chellappan, K. Dua, S. Satija, Emerging trends in the novel drug delivery approaches for the treatment of lung cancer, Chem. Biol. Interact. 309, 2019, 108720-108725.

[6] R. Awasthi, M.J. Rathbone, P.M. Hansbro, M. Bebawy, K. Dua, Therapeutic prospects of microRNAs in cancer treatment through nanotechnology, Drug Deliv. Transl. Res. 8 (1), 2018, 97-110.

[7] R. Awasthi, A. Roseblade, P.M. Hansbro, M.J. Rathbone, K. Dua, M. Bebawy, Nanoparticles in Cancer Treatment: Opportunities and Obstacles, Curr. Drug Targets 19 (14), 2018, 1696-1709.

[8] K. Dua, S.D. Shukla, T. de Jesus Andreoli Pinto, P.M. Hansbro, Nanotechnology: advancing the translational respiratory research, Interv. Med. Appl. Sci. 9 (1), 2017, 39-41.

[9] N. Soni, M. Tekade, P. Kesharwani, P. Bhattacharya, R. Maheshwari, K. Dua, P.M. Hansbro, R.K. Tekade, Recent Advances in Oncological Submissions of Dendrimer, Curr. Pharm. Des. 23 (21), 2017, 3084-3098.

[10] R. Langer, J. Folkman, Polymers for the sustained release of proteins and other macromolecules, Nature 263, 1976, 797-800.

[11] R.H. Prabhu, V.B. Patravale, M.D. Joshi, Polymeric nanoparticles for targeted treatment in oncology: current insights, Int. J. Nanomed. 2, 2015, 1001-1018.

[12] A. Aydiner, I. Yildiz, A. Seyidova, Clinical outcomes and prognostic factors associated with the response to erlotinib in non-small cell lung cancer patients with unknown EGFR mutational status, Asian Pac. J. Cancer Prev. 14 (5), 2013, 3255-3261.

[13] P. Pandey, H. Dureja, Erlotinib: a targeted anticancer drug, Curr. Cancer Ther. Rev. 13 (1), 2017, 3-16. 
[14] C. Zhou, Y.L. Wu, G. Chen, Erlotinib versus chemotherapy as first-line treatment for patients with advanced EGFR mutation positive non-small cell lung cancer, Lancet Oncol. 12 (8), 2011, 735-742.

[15] D. Jawhari, M. Alswisi, M. Ghannam, Bioequivalence of a new generic formulation of Erlotinib hydrochloride 15-mg tablets versus tarceva in healthy volunteers under fasting conditions, J. Bioequiv. Avail. 6, 2014, 1119-1123.

[16] P. Pandey, H. Dureja, Erlotinib in non-small cell lung cancer: from a thought to necessity, Clin. Cancer Drugs 5 (2), 2018, 87-93.

[17] https://www.accessdata.fda.gov/drugsatfda_docs/label/2008/021743s010lbl.pdf, Accessed 29 October 2018.

[18] L. Illum, Chitosan and its use as a pharmaceutical excipient, Pharm. Res. 15 (9), 1998, 1326-1331.

[19] S. Nie, Understanding and overcoming major barriers in cancer nanomedicine, Nanomed. 5 (4), 2010, 523-528.

[20] V. Kumar, P.C. Bhatt, M. Rahman, G. Kaithwas, H. Choudhry, F.A. Xl-Abbasi, F. Anwar, A. Verma, Fabrication, optimization, and characterization of umbelliferone $\beta$-Dgalactopyranoside-loaded PLGA nanoparticles in treatment of hepatocellular carcinoma: in vitro and in vivo studies, Int. J. Nanomed. 12, 2017, 6747-6758.

[21] P. Das, K. Kumar, A. Nambiraj, R. Rajan, R. Awasthi, K. Dua, Potential therapeutic activity of Phlogacanthus thyrsiformis Hardow (Mabb) flower extract and its biofabricated silver nanoparticles against chemically induced urolithiasis in male wistar rats, Int. J. Biol. Macromol. 103, 2017, 621-629.

[22] J.R. Madan, N.P. Ghuge, K. Dua, Formulation and evaluation of proniosomes containing lornoxicam, Drug Deliv. Transl. Res. 6 (5), 2016, 511-518.

[23] J.R. Madan, B.R. Adokar, K. Dua, Development and evaluation of in situ gel of pregabalin, Int. J. Pharm. Investig. 5 (4), 2015, 226-233.

[24] P. Pandey, R.K. Marwaha, A. Nanda, H. Dureja, Spray-dried nanoparticles-inmicroparticles system (NiMS) of acetazolamide using central composite design, Nanosci. Nanotechnol. Asia 6 (2), 2016, 146-156. 
[25] A.O. Elzoghby, W.M. Samy, N.A. Elgindy, Novel spray-dried genipin-crosslinked casein nanoparticles for prolonged release of alfuzosin hydrochloride, Pharm. Res. 30 (2), 2012, 512 522.

[26] H.L. Reddy, R. Murthy, R.S.R Murthy, Etoposide loaded nanoparticles made from glycerides lipids: Formation, characterization, in vitro drug release and stability evaluation, AAPS PharmSciTech. 6 (2), 2015, E158-E166.

[27] A. Gorajana, W.W. Kit, K. Dua, Characterization and solubility study of norfloxacinpolyethylene glycol, polyvinylpyrrolidone and carbopol 974p solid dispersions, Recent Pat. Drug Deliv. Formul. 9 (2), 2015, 167-182.

[28] S. Shivani, K.K. Poladi, Nanosponges - novel emerging drug delivery system: a review, Int. J. Pharm. Sci. Res. 6 (2), 2015 529-540.

[29] G.P. Aithal, J.A. Thomas, P.V. Kaye, A. Lawson, S.D. Ryder, I. Spendlove, A.S. Austin J.G. Freeman, L. Morgan, J. Webber, Randomized, placebo-controlled trial of pioglitazone in nondiabetic subjects with nonalcoholic steatohepatitis, Gastroenterol. 135 (4), 2008, 1176-1184.

[30] K. Singh, A. Singh, A. Mishra, Synthesis, characterization and in vitro release profile of gentamicin loaded chitosan nanoparticle, Int. J. Pharm. Tech. 2, 2016, 29189-29198.

[31] Measuring and characterizing nanoparticle Size-TEM vs SEM, https://www.azonano.com/ article.aspx?ArticleID=4118, Accessed 29 October 2018.

[32] M. Chauhan, G. Joshi, H. Kler, A. Kashyap, S.M. Amrutkar, P. Sharma, K.D. Bhilare, U.C. Banerjee, S. Singh, R. Kumar, Dual inhibitors of epidermal growth factor receptor and topoisomerase II $\alpha$ derived from a quinoline scaffold. RSC Adv. 6 2016, 77717-77734.

[33] G. Joshi, H. Nayyar, S. Kalra, P. Sharma, A. Munshi, S. Singh, R. Kumar, Pyrimidine containing epidermal growth factor kinase inhibitors: synthesis and biological evaluation. Chem. Biol. Drug Design 90 (5), 2012, 995-1006.

[34] K. Dua, Application of model independent approach on in vitro release of extemporaneously prepared semisolid formulations containing metronidazole with marketed silver sulfadiazine 1\% cream, USP: A comparative investigation, Bull. Pharm. Res. 3 (1), 2013, $1-5$.

[35] FDA, Guidance for industry: dissolution testing of immediate release solid oral dosage forms (BP1), Centre for drug evaluation and research, Food and drug administration (1997) Rockville, MD, p9. 
[36] Guidelines for dynamic light scattering measurement and analysis. 2015, http://50.87.149.212/sites/default/files/nan0Composix\%20Guidelines\%20Analysis.pdf, Accessed 5 March 2019.

[37] Z. Bakhtiary, J. Barar, A. Aghanejad, Microparticles containing erlotinib-loaded solid lipid nanoparticles for treatment of non-small cell lung cancer, Drug Devel. Ind. Pharm. 43 (8), 2017, 1244-1253.

[38] N. Pirooznia, S. Hasannia, A.S. Lotfi, M. Ghanei, Encapsulation of alpha-1 antitrypsin in PLGA nanoparticles: In vitro characterization as an effective aerosol formulation in pulmonary diseases, J. Nanobiotechnol. 10 (20), 2012, 1-15.

[39] X. Zhou, B. Yung, Y. Huang, H. Li, X. Hu, G. Xiang, R.J. Lee, Novel liposomal geftinib (L-GEF) formulations, Anticancer Res. 32 (7), 2012, 2919-2923.

[40] S.S. Zhang, J. Li, G. Lyktotrafitis, Size dependent endocytosis of nanoparticles, Adv. Mater. 21, 2009, 419-424. 
Table 1 Central Composite Designed Erlotinib Loaded Chitosan Nanoparticles using Sonication Technique.

Table 2 Characterization of Central Composite Designed Erlotinib Loaded Chitosan Nanoparticles.

Table 3 ANOVA of the Regression.

Table 4 Effect of Storage Temperature on Characteristics of Central Composite Designed Erlotinib Loaded Chitosan Nanoparticles using Sonication Technique.

Table 5 Comparison of Optimized Formulation with Pure Drug and Marketed Tablets.

Table $6 \mathrm{IC}_{50}$ values of the Pure Drug Erlotinib Hydrochloride and the Central Composite Designed Erlotinib Loaded Chitosan Nanoparticles. 
Table 1

\begin{tabular}{|l|l|l|l|}
\hline $\begin{array}{l}\text { Formulation } \\
\text { Code }\end{array}$ & $\begin{array}{l}\text { Concentration of Chitosan } \\
\left(\text { percent w/v) }\left(\mathbf{X}_{\mathbf{1}}\right)\right.\end{array}$ & $\begin{array}{l}\text { Concentration of NaTPP } \\
\left(\text { percent w/v) } \mathbf{X}_{\mathbf{2}}\right)\end{array}$ & $\begin{array}{l}\text { Sonication Time } \\
(\mathbf{m i n})\left(\mathbf{X}_{\mathbf{3}}\right)\end{array}$ \\
\hline NP-1 & $-1(0.1)$ & $-1(0.2)$ & $-1(14)$ \\
\hline NP-2 & $+1(0.2)$ & $-1(0.2)$ & $-1(14)$ \\
\hline NP-3 & $-1(0.1)$ & $+1(0.3)$ & $-1(14)$ \\
\hline NP-4 & $+1(0.2)$ & $+1(0.3)$ & $-1(14)$ \\
\hline NP-5 & $-1(0.1)$ & $-1(0.2)$ & $+1(20)$ \\
\hline NP-6 & $+1(0.2)$ & $-1(0.2)$ & $+1(20)$ \\
\hline NP-7 & $-1(0.1)$ & $+1(0.3)$ & $+1(20)$ \\
\hline NP-8 & $+1(0.2)$ & $+1(0.3)$ & $+1(20)$ \\
\hline NP-9 & $-1.682(0.0659)$ & $0(0.25)$ & $0(17)$ \\
\hline NP-10 & $+1.682(0.234)$ & $0(0.25)$ & $0(17)$ \\
\hline NP-11 & $0(0.15)$ & $-1.682(0.166)$ & $0(17)$ \\
\hline NP-12 & $0(0.15)$ & $+1.682(0.334)$ & $0(17)$ \\
\hline NP-13 & $0(0.15)$ & $0(0.25)$ & $-1.682(11.95)$ \\
\hline NP-14 & $0(0.15)$ & $0(0.25)$ & $+1.682(22.04)$ \\
\hline NP-15 & $0(0.15)$ & $0(0.25)$ & $0(17)$ \\
\hline NP-16 & $0(0.15)$ & $0(0.25)$ & $0(17)$ \\
\hline NP-17 & $0(0.15)$ & $0(0.25)$ & $0(17)$ \\
\hline NP-18 & $0(0.15)$ & $0(0.25)$ & $0(17)$ \\
\hline
\end{tabular}

*The values in bracket indicate real values 
Table 2

\begin{tabular}{|l|l|l|l|l|l|l|}
\hline $\begin{array}{l}\text { Formulation } \\
\text { Code }\end{array}$ & $\begin{array}{l}\text { Particle Size } \\
(\mathbf{n m})\end{array}$ & PDI & $\begin{array}{l}\text { Zeta } \\
\text { Potential }\end{array}$ & $\begin{array}{l}\text { Percentage } \\
\text { Yield } \\
\text { (percent) }\end{array}$ & $\begin{array}{l}\text { Loading } \\
\text { Capacity } \\
\text { (percent) }\end{array}$ & $\begin{array}{l}\text { Entrapment } \\
\text { Efficiency } \\
\text { (percent) }\end{array}$ \\
\hline NP-1 & 250.8 & 0.783 & 26.9 & 68.07 & $69.23 \pm 0.45$ & $41.54 \pm 0.54$ \\
\hline NP-2 & 242.7 & 0.534 & 24.1 & 66.60 & $61.22 \pm 0.15$ & $44.33 \pm 0.42$ \\
\hline NP-3 & 134.7 & 0.469 & 28.4 & 74.77 & $69.55 \pm 0.48$ & $42.69 \pm 0.77$ \\
\hline NP-4 & 139.7 & 0.392 & 31.7 & 71.89 & $63.46 \pm 0.34$ & $34.02 \pm 0.26$ \\
\hline NP-5 & 549.1 & 0.922 & 24.7 & 64.43 & $73.84 \pm 0.41$ & $47.62 \pm 0.17$ \\
\hline NP-6 & 511.2 & 0.385 & 21.9 & 62.10 & $65.46 \pm 0.85$ & $38.14 \pm 0.34$ \\
\hline NP-7 & 138.5 & 0.382 & 26.3 & 67.44 & $77.15 \pm 0.15$ & $49.02 \pm 0.24$ \\
\hline NP-8 & 589.5 & 0.720 & 22.2 & 63.00 & $68.12 \pm 0.38$ & $39.20 \pm 0.35$ \\
\hline NP-9 & 282.5 & 0.462 & 23.8 & 65.22 & $70.95 \pm 0.23$ & $33.62 \pm 0.25$ \\
\hline NP-10 & 753.5 & 0.778 & 15.9 & 66.34 & $63.35 \pm 0.41$ & $37.58 \pm 0.47$ \\
\hline NP-11 & 288.6 & 0.798 & 16.2 & 59.94 & $70.74 \pm 0.20$ & $43.33 \pm 0.49$ \\
\hline NP-12 & 335.9 & 0.353 & 24.5 & 64.10 & $70.69 \pm 0.14$ & $44.28 \pm 0.56$ \\
\hline NP-13 & 83.06 & 0.295 & 13.5 & 67.25 & $68.19 \pm 0.32$ & $41.22 \pm 0.44$ \\
\hline NP-14 & 756.2 & 0.516 & 18.1 & 58.86 & $72.39 \pm 0.24$ & $46.43 \pm 0.62$ \\
\hline NP-15 & 419.8 & 0.481 & 26.2 & 66.80 & $71.88 \pm 0.29$ & $45.50 \pm 0.31$ \\
\hline NP-16 & 450.7 & 0.405 & 25.9 & 66.95 & $71.21 \pm 0.16$ & $45.36 \pm 0.13$ \\
\hline NP-17 & 460.8 & 0.658 & 25.8 & 66.21 & $71.97 \pm 0.61$ & $45.58 \pm 0.19$ \\
\hline NP-18 & 434.8 & 0.412 & 25.4 & 67.10 & $72.18 \pm 0.45$ & $45.11 \pm 0.32$ \\
\hline
\end{tabular}


Table 3

\begin{tabular}{|c|c|c|c|c|c|c|c|c|}
\hline S. No. & Response & $\begin{array}{l}\text { Source of } \\
\text { Variation }\end{array}$ & $\begin{array}{l}\text { Degree of } \\
\text { Freedom }\end{array}$ & $\begin{array}{c}\text { Sum of } \\
\text { Squares }\end{array}$ & Mean Square & F-Value & P-Value & \\
\hline 1. & Particle Size & Residual & 8 & 124818.98 & 15602.37 & - & $0.0289^{*}$ & Significant \\
\hline \multirow[t]{3}{*}{2.} & \multirow{3}{*}{$\begin{array}{l}\text { Entrapment } \\
\text { Efficiency }\end{array}$} & Model & 9 & 250.87 & 27.87 & 9.41 & \multirow[t]{3}{*}{$0.0022 *$} & \multirow[t]{3}{*}{ Significant } \\
\hline & & Residual & 8 & 23.69 & 2.96 & - & & \\
\hline & & Total & 17 & 274.56 & - & - & & \\
\hline 3. & $\begin{array}{c}\text { Percent } \\
\text { Cumulative Drug } \\
\text { Release in } 0.1 \mathrm{~N} \\
\text { hydrochloric acid }\end{array}$ & Total & 17 & 366.56 & - & - & $0.0408 *$ & Significant \\
\hline \multirow[t]{3}{*}{4.} & \multirow{3}{*}{$\begin{array}{c}\text { Percent } \\
\text { Cumulative Drug } \\
\text { Release in PB pH } \\
6.8\end{array}$} & Model & 9 & 485.55 & 53.95 & 4.27 & \multirow[t]{3}{*}{$0.0264 *$} & \multirow[t]{3}{*}{ Significant } \\
\hline & & Residual & 8 & 101.01 & 12.63 & - & & \\
\hline & & Total & 17 & 586.55 & - & - & & \\
\hline
\end{tabular}

$* \mathrm{P}<0.05$ 
Table 4

\begin{tabular}{|c|c|c|c|c|c|}
\hline \multirow{2}{*}{$\begin{array}{l}\text { Evaluation } \\
\text { Parameter }\end{array}$} & \multirow[t]{2}{*}{ Temperature } & \multicolumn{4}{|c|}{ Time Intervals in Months } \\
\hline & & 1 & 2 & 3 & 6 \\
\hline \multirow[t]{3}{*}{ Particle Size (nm) } & $4^{\circ} \mathrm{C}$ & 144.6 & 151.2 & 159.5 & 167.9 \\
\hline & $\begin{array}{l}\text { Room } \\
\text { Temperature }\end{array}$ & 146.6 & 153.5 & 162.0 & 173.2 \\
\hline & $45^{\circ} \mathrm{C}$ & 152.1 & 158.1 & 166.4 & 177.4 \\
\hline \multirow{3}{*}{$\begin{array}{l}\text { Percent Cumulative } \\
\text { Drug Release in } 0.1 \mathrm{~N} \\
\text { Hydrochloric Acid }\end{array}$} & $4^{\circ} \mathrm{C}$ & $90.22 \pm 0.12$ & $89.68 \pm 0.23$ & $88.70 \pm 0.11$ & $87.78 \pm 0.22$ \\
\hline & $\begin{array}{l}\text { Room } \\
\text { Temperature }\end{array}$ & $89.76 \pm 0.15$ & $88.97 \pm 0.14$ & $88.02 \pm 0.17$ & $87.12 \pm 0.24$ \\
\hline & $45^{\circ} \mathrm{C}$ & $88.58 \pm 0.08$ & $87.72 \pm 0.19$ & $87.23 \pm 0.07$ & $86.76 \pm 0.29$ \\
\hline \multirow{3}{*}{$\begin{array}{l}\text { Percent Cumulative } \\
\text { Drug Release in PB } \\
\text { pH } 6.8\end{array}$} & $4^{\circ} \mathrm{C}$ & $39.47 \pm 0.10$ & $39.30 \pm 0.05$ & $39.12 \pm 0.11$ & $38.90 \pm 0.13$ \\
\hline & $\begin{array}{l}\text { Room } \\
\text { Temperature }\end{array}$ & $39.34 \pm 0.21$ & $39.10 \pm 0.12$ & $38.96 \pm 0.20$ & $38.65 \pm 0.17$ \\
\hline & $45^{\circ} \mathrm{C}$ & $39.24 \pm 0.18$ & $38.92 \pm 0.19$ & $38.80 \pm 0.14$ & $38.33 \pm 0.08$ \\
\hline
\end{tabular}


Table 5

\begin{tabular}{|c|c|c|c|c|c|c|}
\hline \multirow[t]{2}{*}{$\begin{array}{l}\text { Time } \\
\text { Interval }\end{array}$} & \multicolumn{2}{|c|}{$\begin{array}{l}\text { Percent Cumulative Amount of Drug } \\
\text { Released from Optimized Batch in } \\
\text { Different Media }\end{array}$} & \multicolumn{2}{|c|}{$\begin{array}{l}\text { Percent Cumulative Amount of } \\
\text { Drug Released from Pure Drug in } \\
\text { Different Media }\end{array}$} & \multicolumn{2}{|c|}{$\begin{array}{l}\text { Percent Cumulative Amount of Drug } \\
\text { Released from Marketed Tablet in } \\
\text { Different Media }\end{array}$} \\
\hline & $\begin{array}{l}\text { 0.1 N Hydrochloric } \\
\text { Acid }\end{array}$ & PB pH 6.8 & $\begin{array}{l}\text { 0.1 N Hydrochloric } \\
\text { Acid }\end{array}$ & PB pH 6.8 & $\begin{array}{l}\text { 0.1 N Hydrochloric } \\
\text { Acid }\end{array}$ & PB pH 6.8 \\
\hline 0.5 & $6.12 \pm 0.26$ & $1.12 \pm 0.12$ & $64.22 \pm 0.06$ & $19.45 \pm 0.21$ & $80.12 \pm 0.34$ & $25.56 \pm 0.46$ \\
\hline 1 & $10.86 \pm 1.02$ & $2.56 \pm 0.34$ & $65.09 \pm 0,18$ & $21.69 \pm 0.14$ & $81.46 \pm 0.23$ & $26.78 \pm 0.12$ \\
\hline 2 & $17.43 \pm 1.31$ & $4.89 \pm 0.43$ & $66.89 \pm 0.24$ & $24.65 \pm 0.18$ & $83.54 \pm 0.18$ & $28.92 \pm 0.24$ \\
\hline 4 & $31.45 \pm 1.24$ & $9.22 \pm 0.15$ & $69.32 \pm 0.09$ & $27.94 \pm 0.10$ & $84.88 \pm-0.46$ & $31.65 \pm 0.32$ \\
\hline 6 & $37.67 \pm 1.87$ & $14.58 \pm 0.18$ & $72.23 \pm 0.11$ & $29.89 \pm 0.22$ & $87.92 \pm 0.32$ & $33.56 \pm 0.42$ \\
\hline 8 & $45.20 \pm 1.65$ & $20.78 \pm 0.26$ & $75.55 \pm 0.25$ & $31.56 \pm 0.11$ & $88.23 \pm 0.45$ & $36.78 \pm 0.15$ \\
\hline 12 & $58.17 \pm 1.62$ & $26.16 \pm 0.54$ & $78.76 \pm 0.31$ & $35.03 \pm 0.17$ & $90.89 \pm 0.56$ & $39.84 \pm 0.45$ \\
\hline 18 & $76.88 \pm 1.41$ & $32.88 \pm 0.27$ & $80.92 \pm 0.28$ & $38.66 \pm 0.09$ & $93.46 \pm 0.46$ & $42.90 \pm 0.38$ \\
\hline 24 & $91.57 \pm 1.32$ & $39.78 \pm 0.78$ & $83.77 \pm 0.15$ & $42.12 \pm 0.16$ & $95.76 \pm 0.28$ & $44.54 \pm 0.42$ \\
\hline
\end{tabular}


Table 6

\begin{tabular}{|l|c|c|}
\hline S. No. & Treatment & Ic $_{\mathbf{5 0}}$ Value (Mm) \\
\hline 1. & Pure Drug & $1.03 \pm 0.02$ \\
\hline 2. & NP-13 & $5.95 \pm 0.08$ \\
\hline 3. & NP-7 & $6.36 \pm 0.09$ \\
\hline
\end{tabular}


Fig. 1. Structure of Erlotinib.

Fig. 2. Pictorial representation of preparation of erlotinib loaded chitosan nanoparticles.

Fig. 3. (a) Particle Size Analysis and Polydispersity Index of NP - 7 (b) Pareto Chart for Coefficients of Particle Size (b1, b2, b3 = coefficients of main terms; b4, b5, b6 = coefficients of interaction terms and b7, b8, b9 = coefficients of square terms). (c) 3D Response Surface Plot indicating the effect of different process variables on Particle Size. (d) Contour Plot indicating the effect of different process variables on Particle Size.

Fig. 4. (a) Pareto Chart for Coefficients of Entrapment Efficiency (b1, b2, b3 = coefficients of main terms; b4, b5, b6 = coefficients of interaction terms and b7, b8, b9 = coefficients of square terms). (b) 3D Response Surface Plot indicating the effect of different process variables on Entrapment Efficiency. (c) Contour Plot indicating the effect of different process variables on Entrapment Efficiency.

Fig. 5. (a) Pareto Chart for Coefficients of percent Cumulative Drug Release in $0.1 \mathrm{~N}$ Hydrochloric Acid (b1, b2, b3 = coefficients of main terms; b4, b5, b6 = coefficients of interaction terms and b7, b8, b9 = coefficients of square terms). (b) 3D Response Surface indicating the effect of different process variables on percent Cumulative Drug Release in 0.1N Hydrochloric Acid. (c) Contour Plot indicating the effect of different process variables on percent Cumulative Drug Release in 0.1N Hydrochloric Acid.

Fig. 6. (a) Pareto Chart for Coefficients of percent Cumulative Drug Release in PB pH 6.8 (b1, b2, b3 = coefficients of main terms; b4, b5, b6 = coefficients of interaction terms and b7, b8, b9 = coefficients of square terms). (b) 3D Response Surface indicating the effect of different process variables on percent Cumulative Drug Release in $\mathrm{PB} \mathrm{pH}$ 6.8. (c) Contour Plot indicating the effect of different process variables on percent Cumulative Drug Release in PB pH 6.8.

Fig. 7. (a) An Overlay of DSC Thermograms of Erlotinib, Chitosan and the Optimized Batch NP-7. (b) An Overlay of DSC Thermograms of Central Composite Designed Erlotinib Loaded Chitosan Nanoparticles of NP-1 to NP-6. (c) An Overlay of DSC Thermograms of Central Composite Designed Erlotinib Loaded Chitosan Nanoparticles of NP-7 to NP-12. (d) An Overlay of DSC Thermograms of Central Composite Designed Erlotinib Loaded Chitosan Nanoparticles of NP-13 to NP-18.

Fig. 8. (a) ATR Spectrum of Erlotinib Hydrochloride, Chitosan and the Optimized Batch NP-7. (b) An Overlay of ATR of Central Composite Designed Erlotinib Loaded Chitosan Nanoparticles of NP-1 to NP-6. (c) An Overlay of ATR of Central Composite Designed Erlotinib Loaded Chitosan Nanoparticles of NP-7 to NP-12. An Overlay of ATR of Central Composite Designed Erlotinib Loaded Chitosan Nanoparticles of NP-13 to NP-18.

Fig. 9. (a) XRD of the Pure Drug - Erlotinib Hydrochloride (b) XRD of the Polymer - Chitosan (c) XRD of Optimized Batch NP-7.

Fig. 10. TEM of Optimized Batch NP-7. 


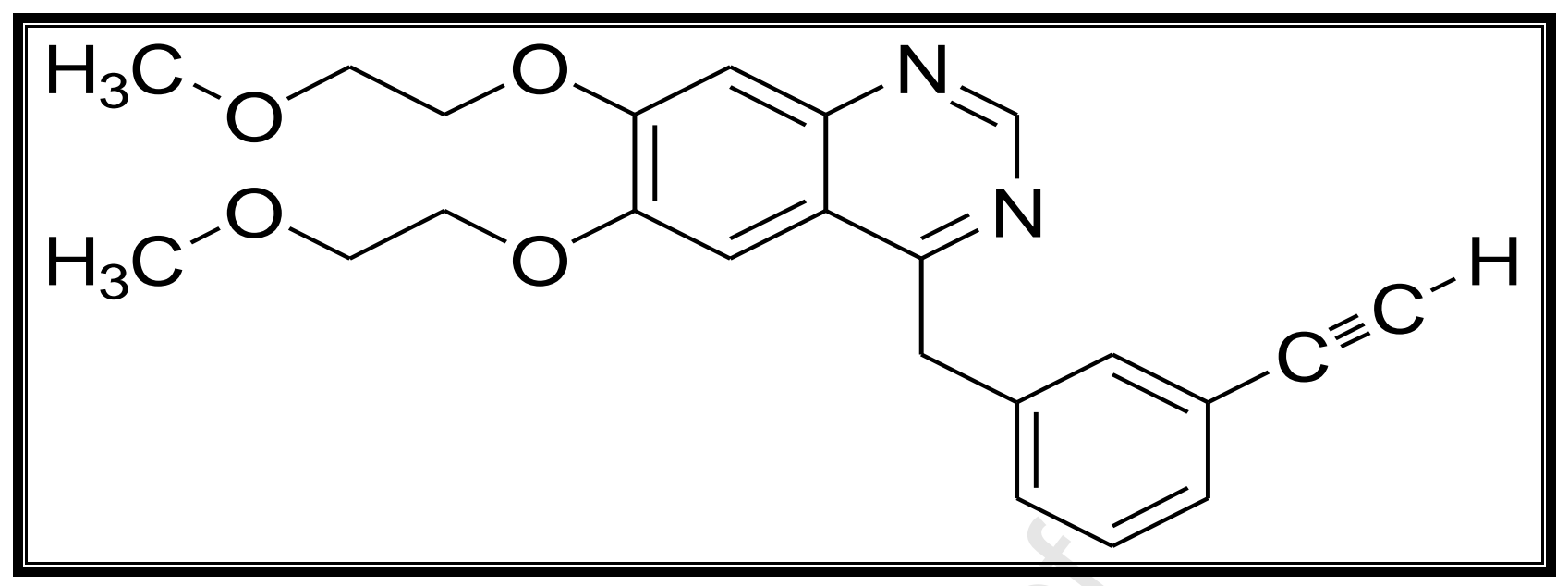

Fig. 1. 
Chitosan $(0.1-0.3$ percent w/v) dissolved in glacial acetic acid $(0.2$ percent v/v).

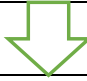

Solution of NaTPP $(0.2-0.3$ percent w/v $)$ using double distilled water.

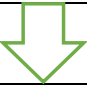

Solution of erlotinib (150 mg) in methanol and dimethyl sulphoxide (1:1) along with the surface stabilizers - PEG 600 (50 mg).

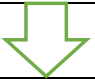

Mixing of chitosan and erlotinib solution at the speed of $1000-1200 \mathrm{rpm}$ for $\sim 4 \mathrm{~h}$

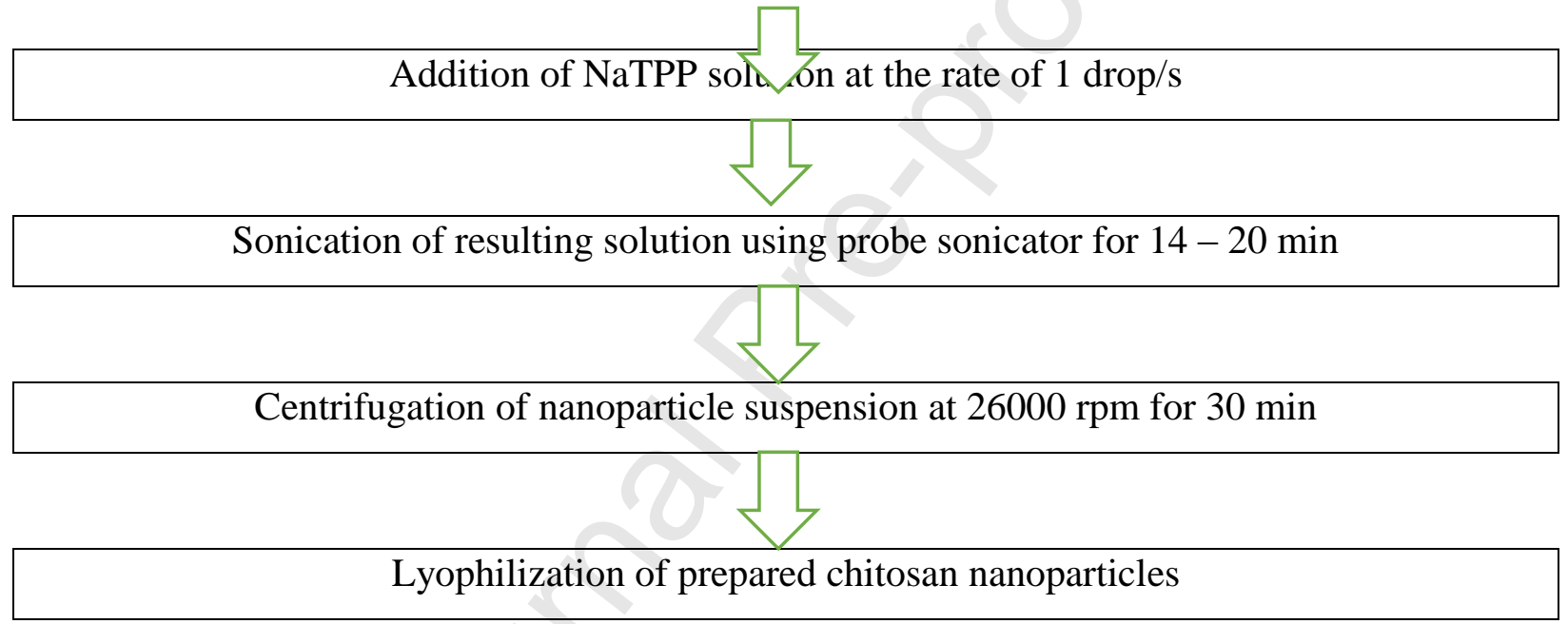

Fig. 2. 

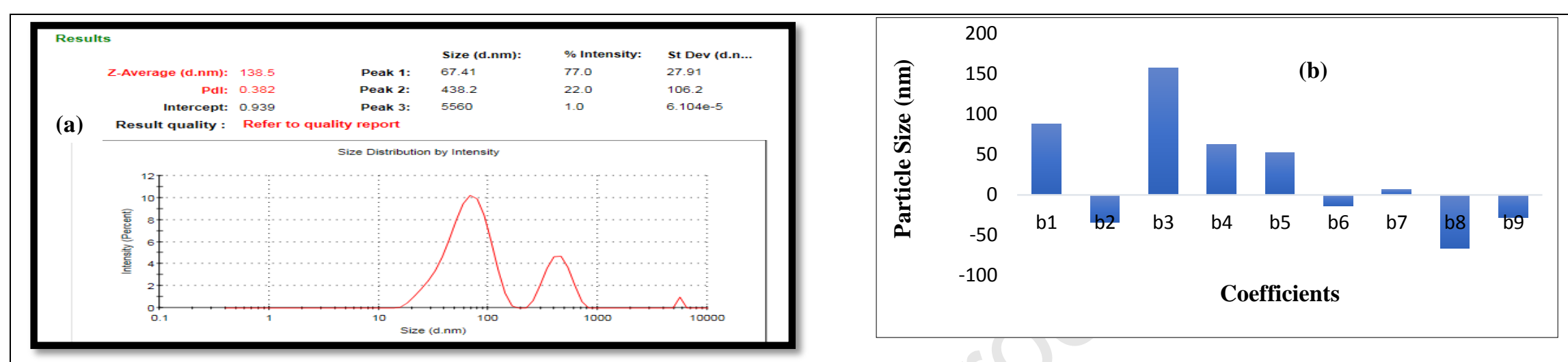

(c)
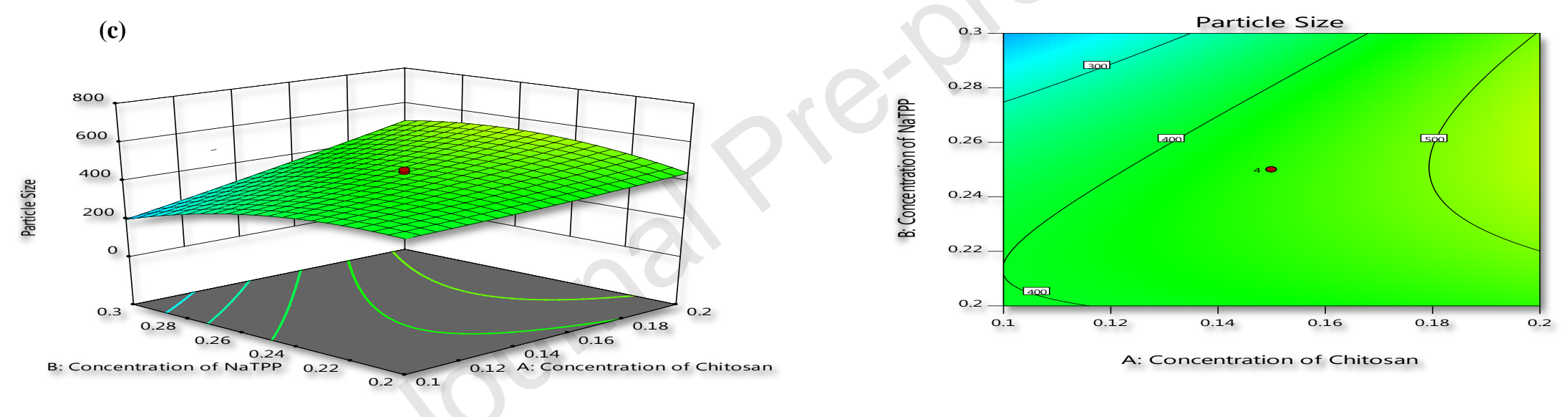

Fig. 3. 


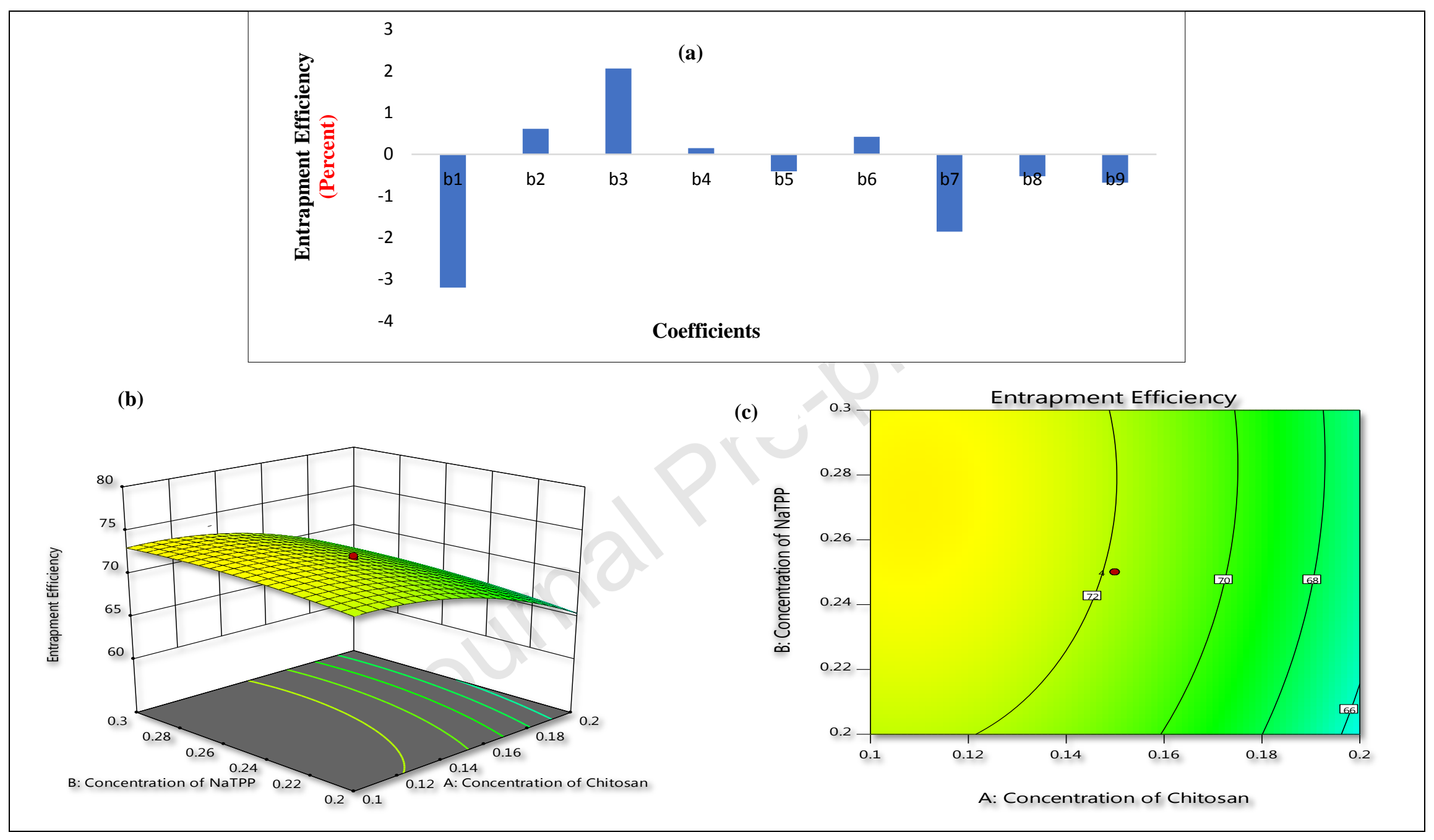

Fig. 4. 


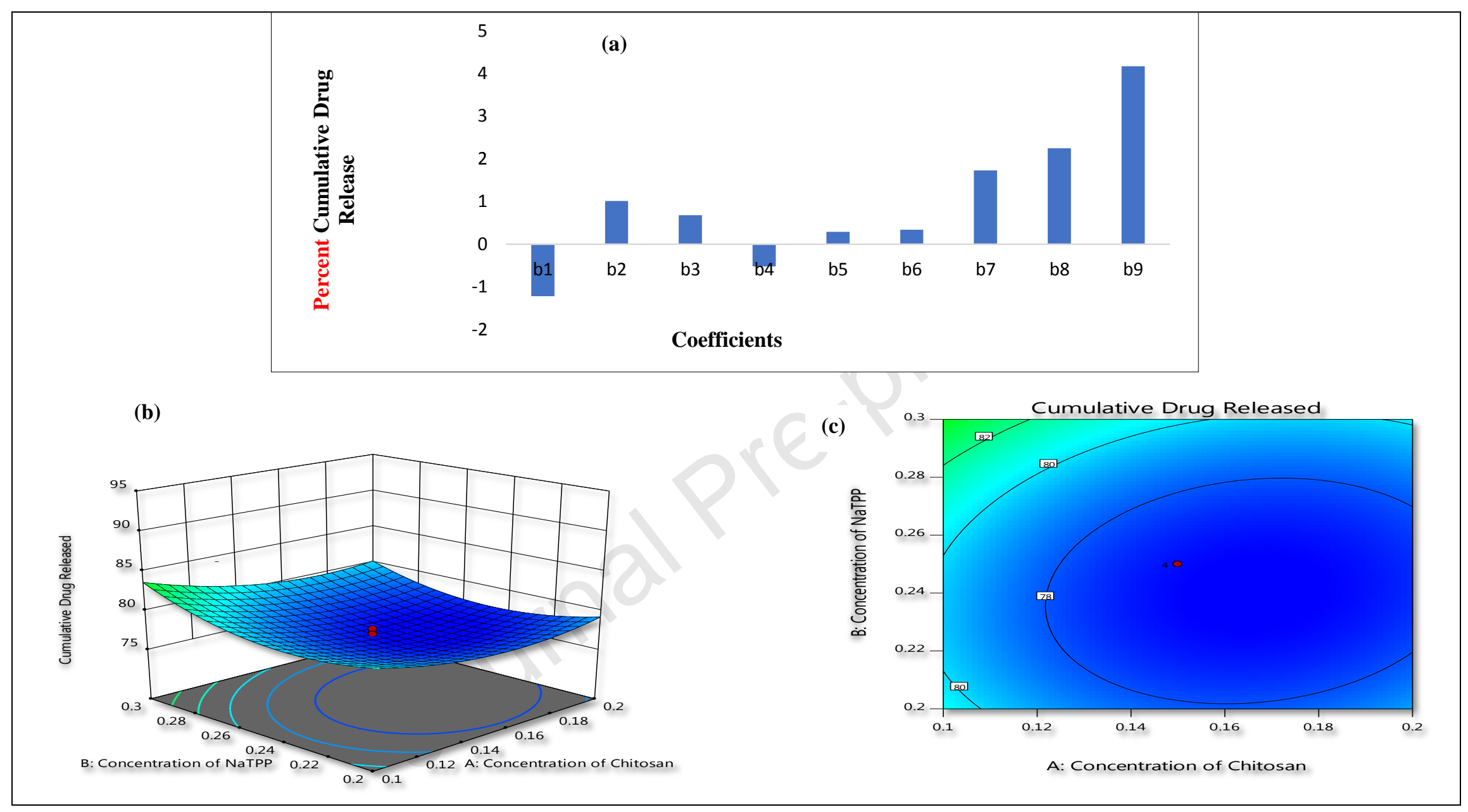

Fig. 5. 


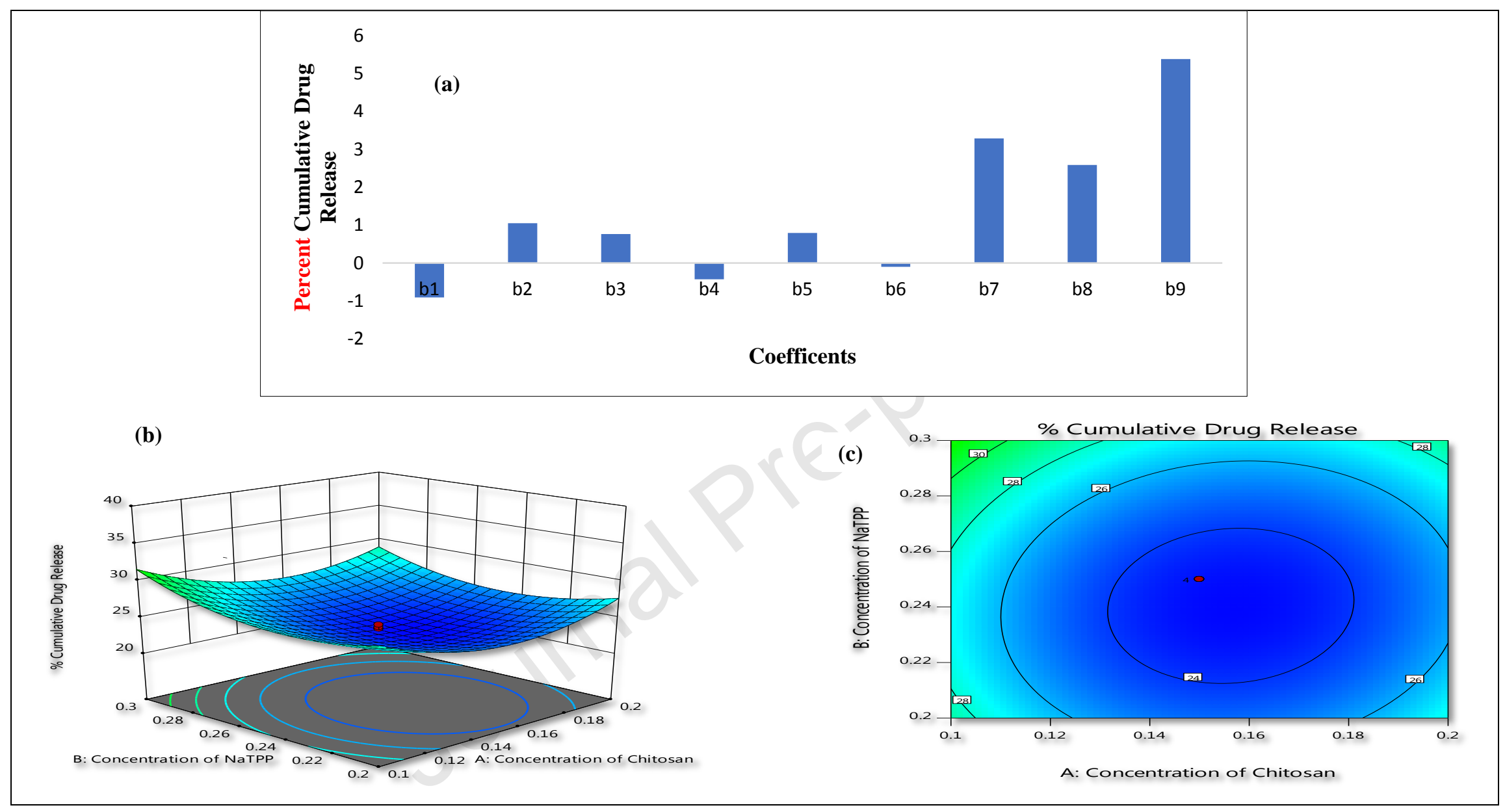

Fig. 6. 


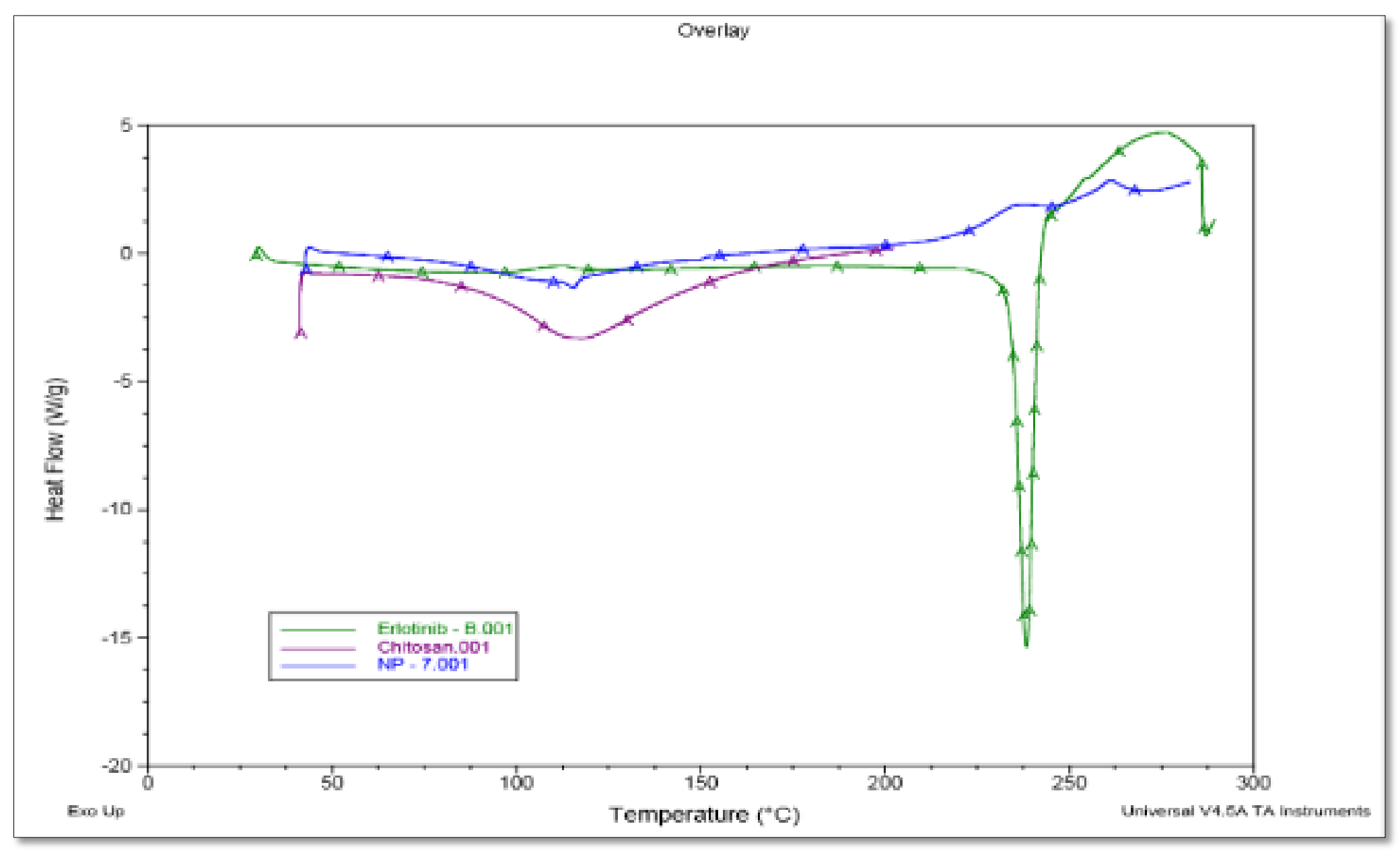

Fig. 7a 


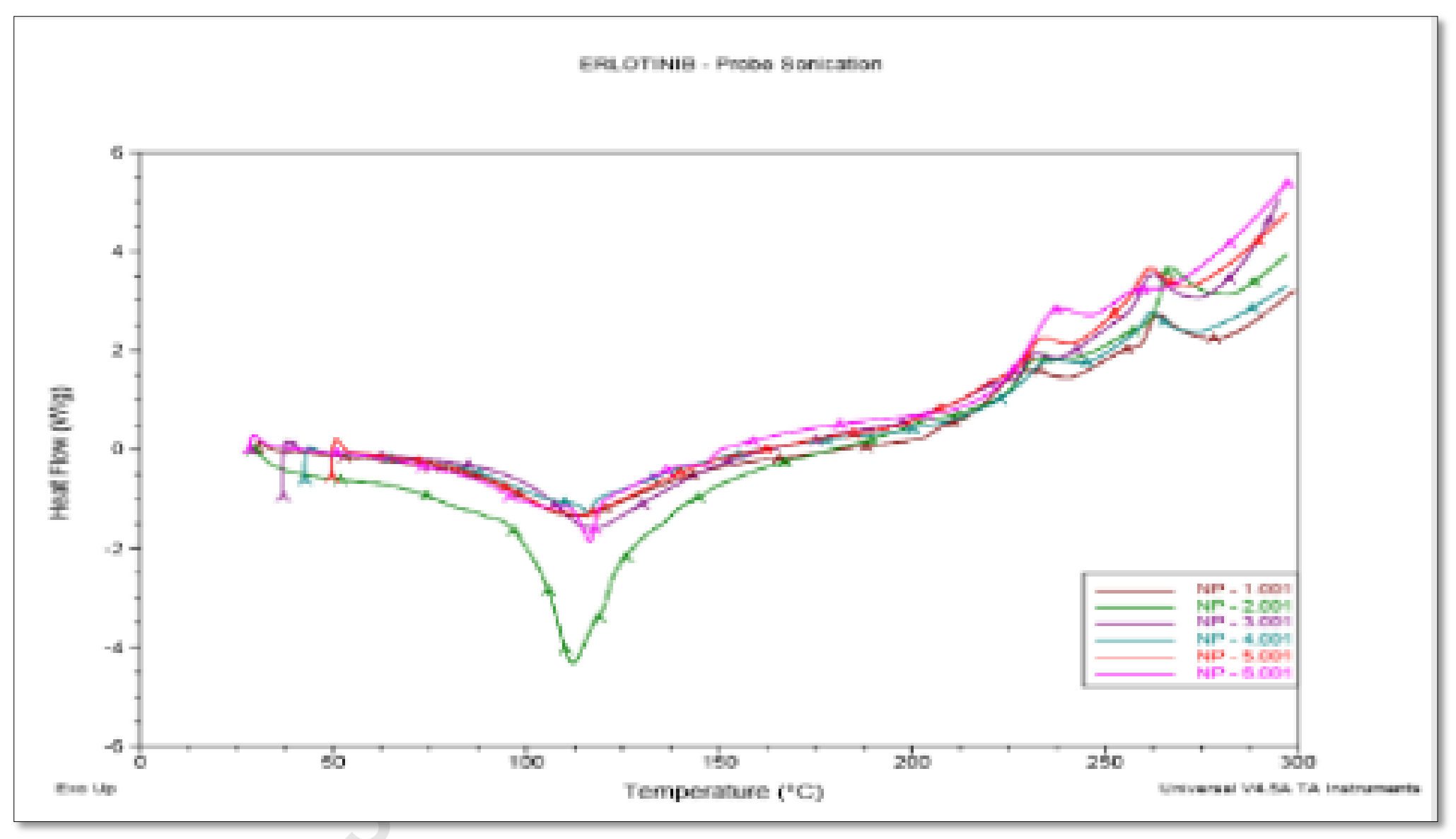

Fig. 7b 


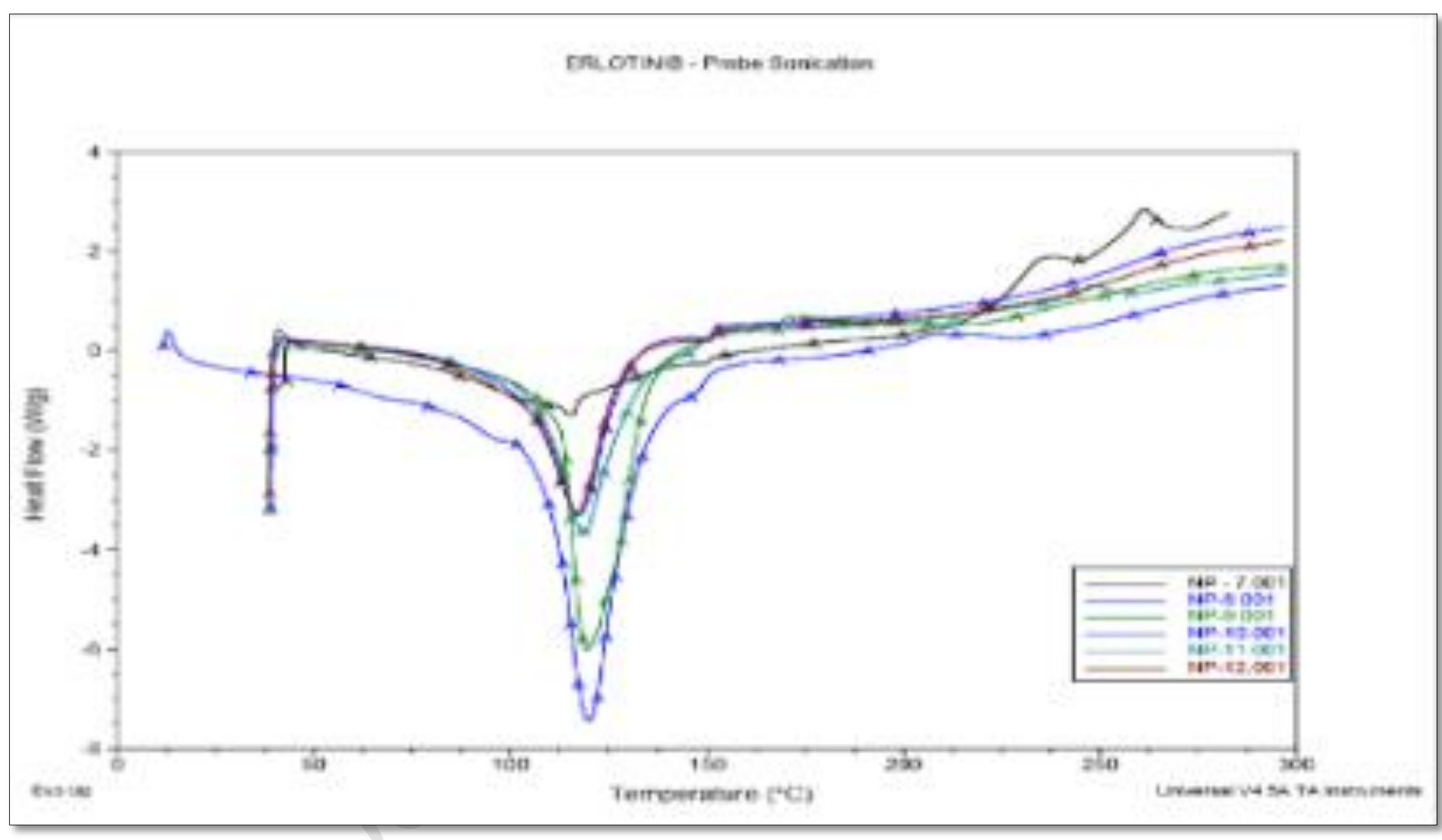

Fig. 7c 


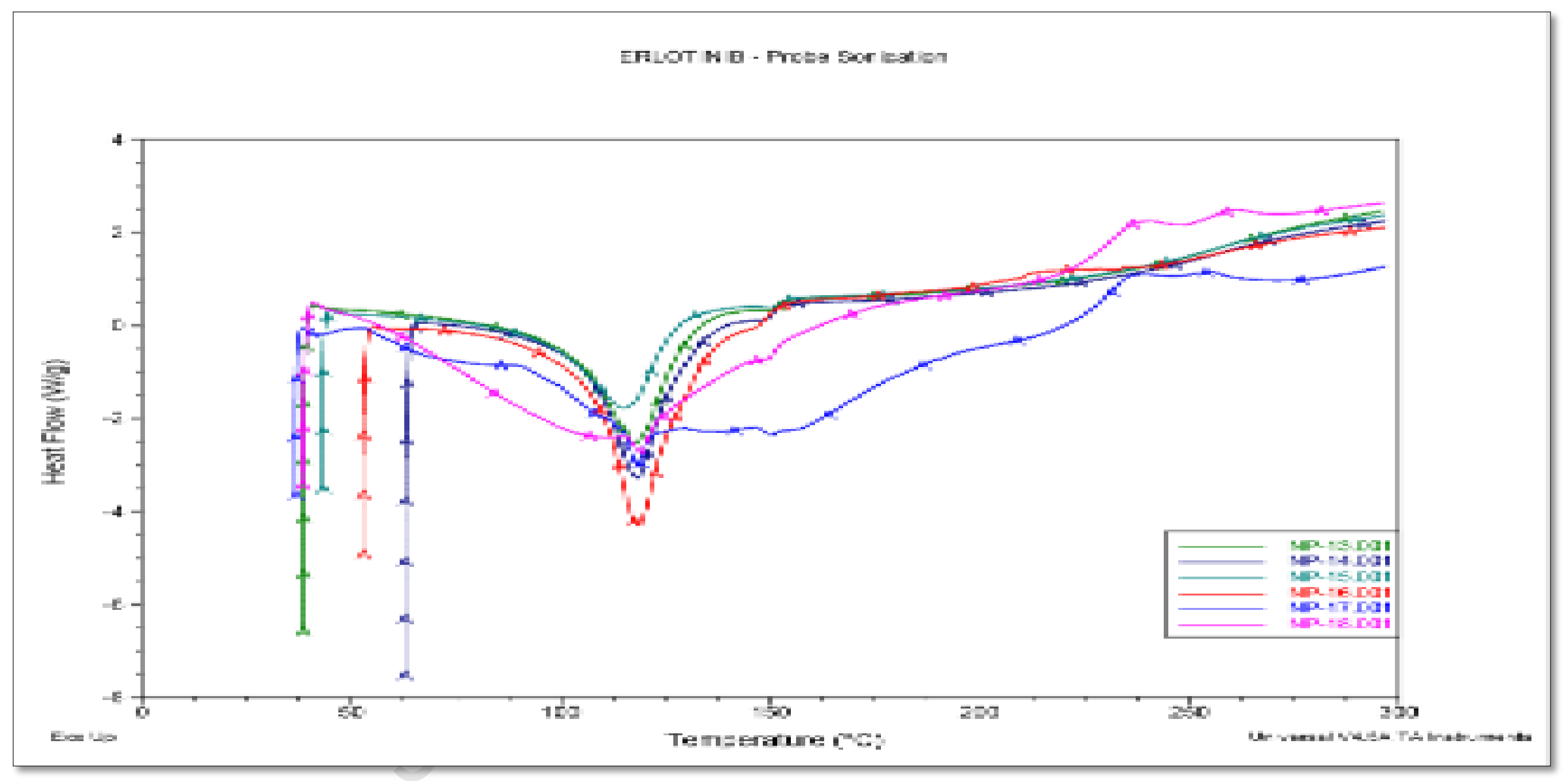

Fig. 7d 


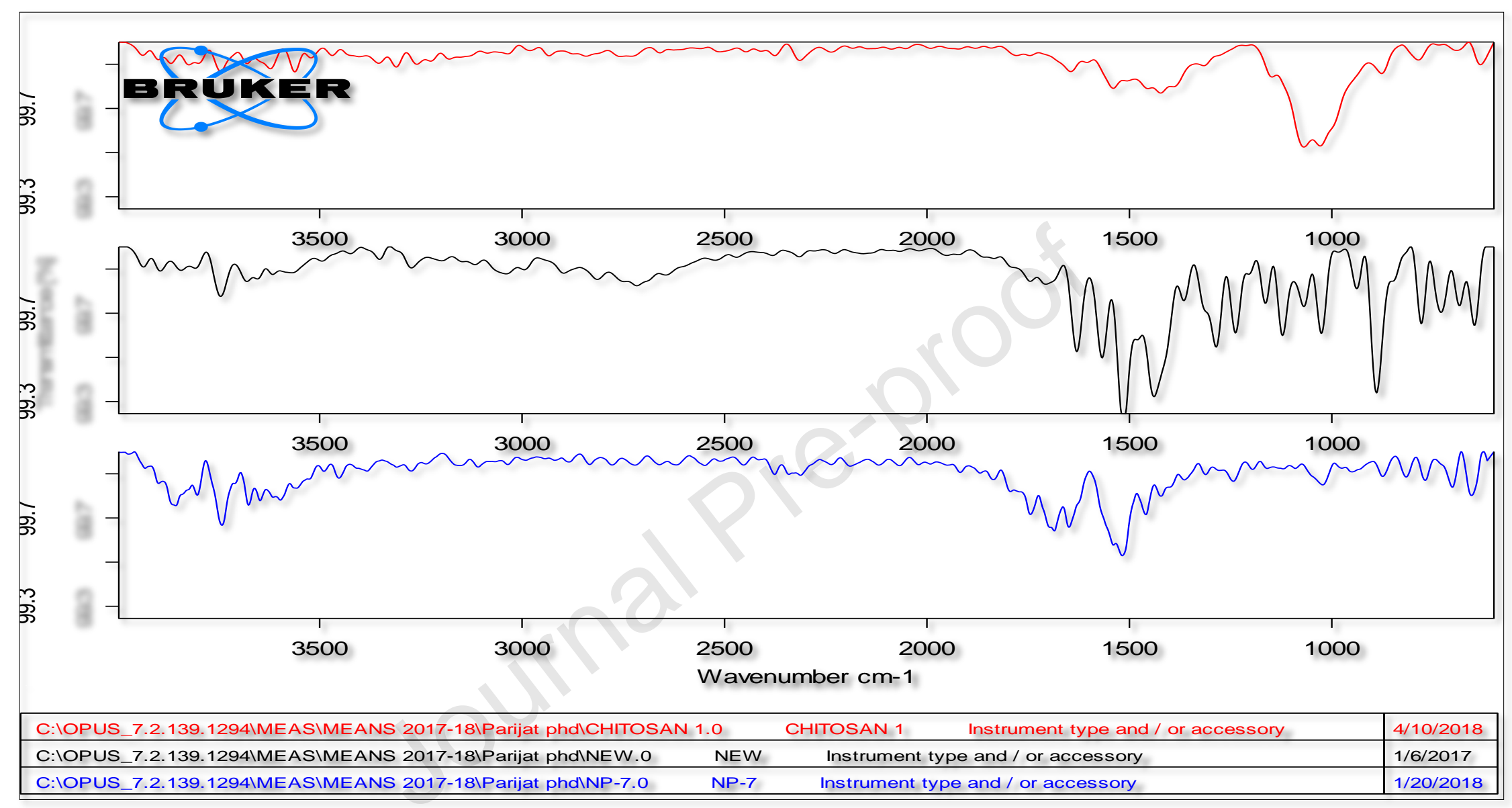

Fig. 8a 


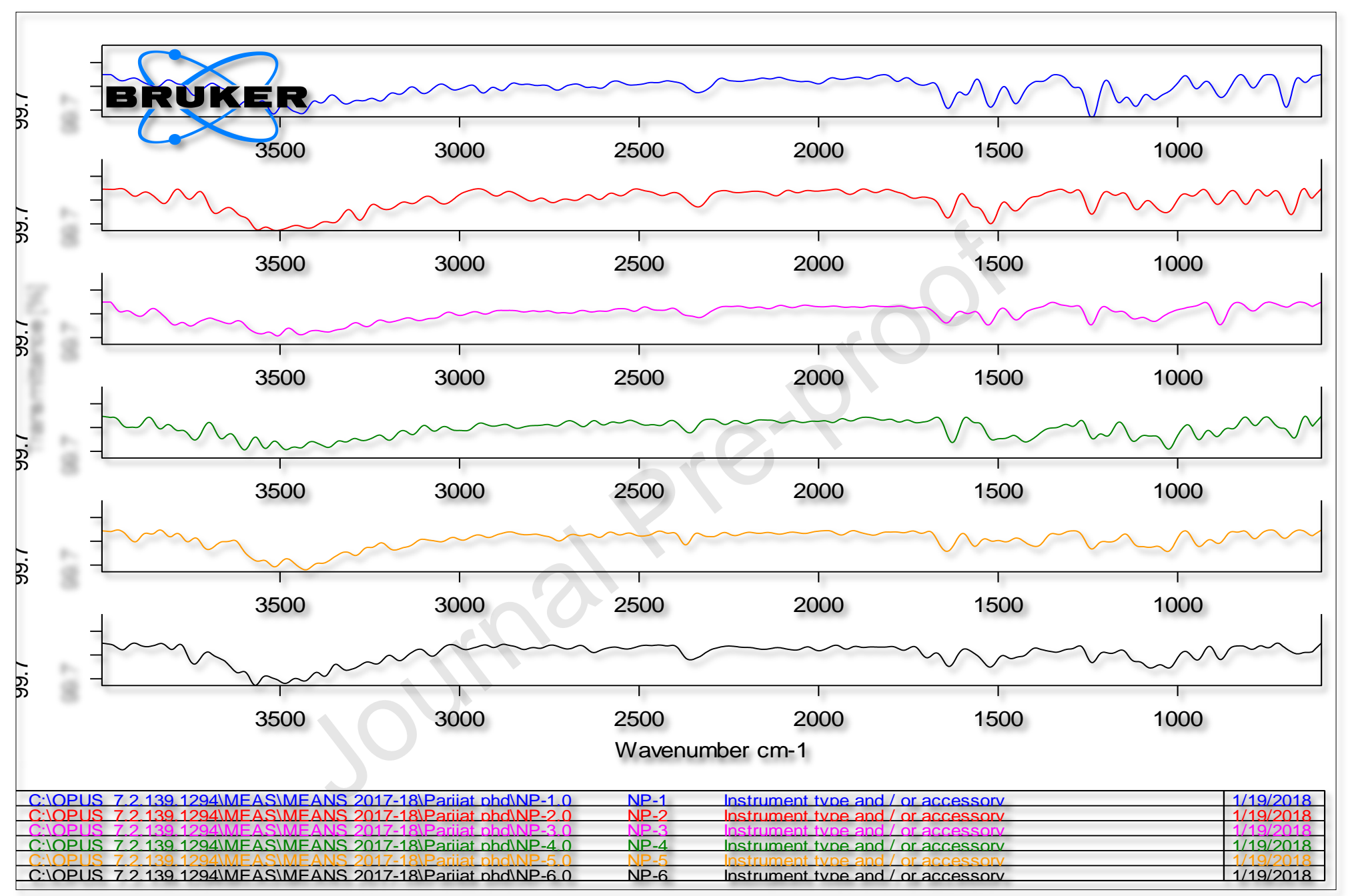

Fig. 8b 


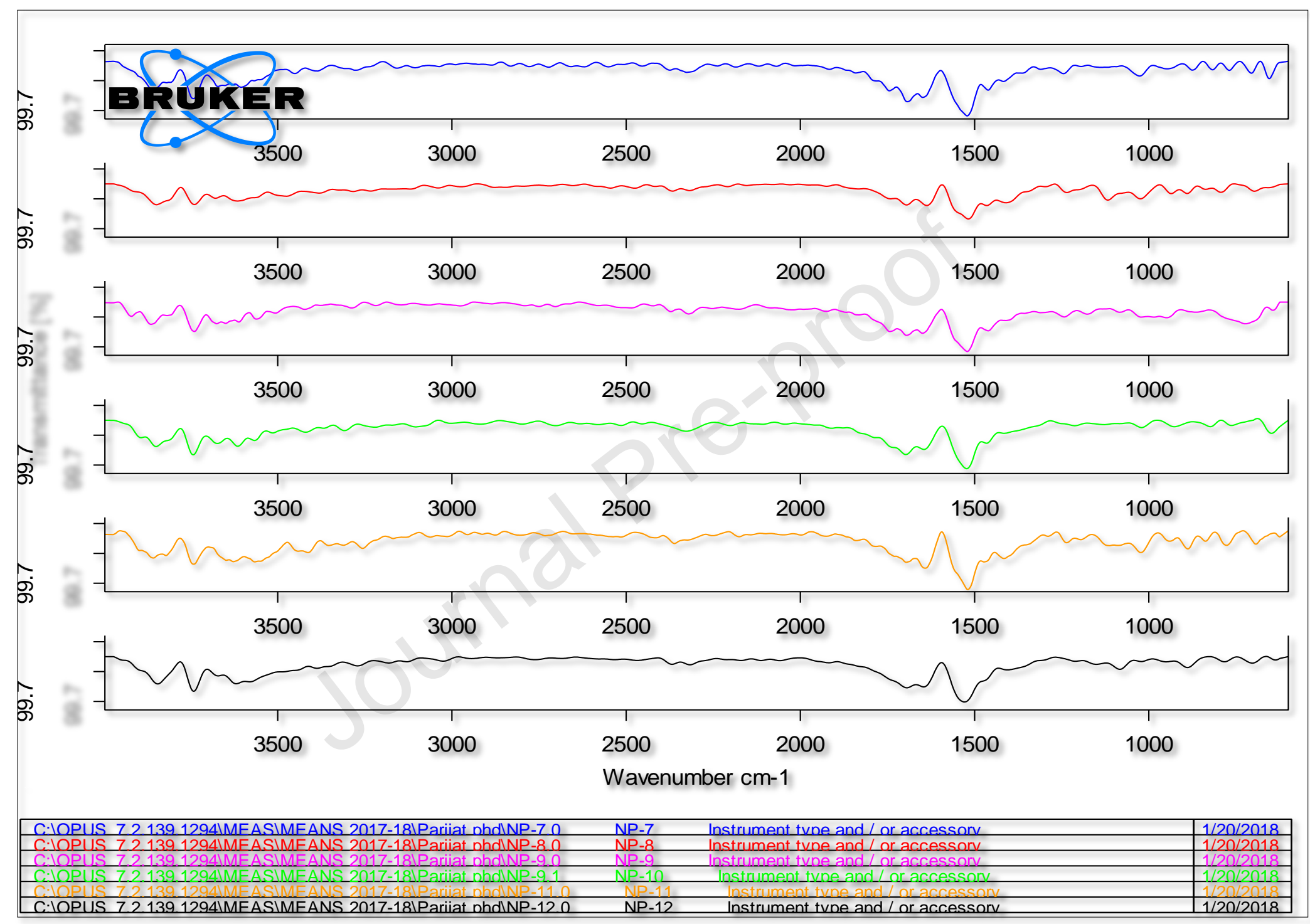

Fig. 8c 


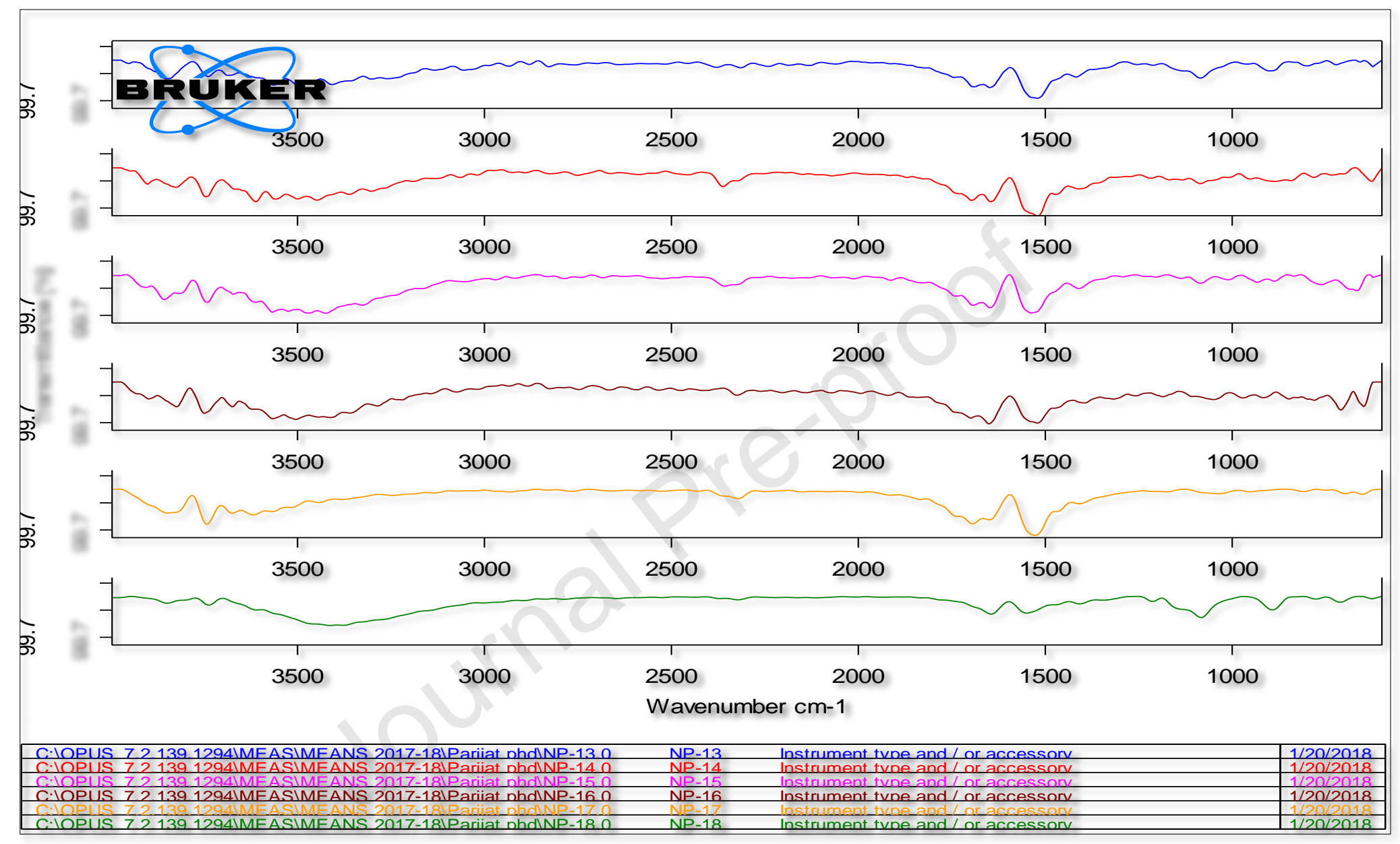

Fig. 8d 


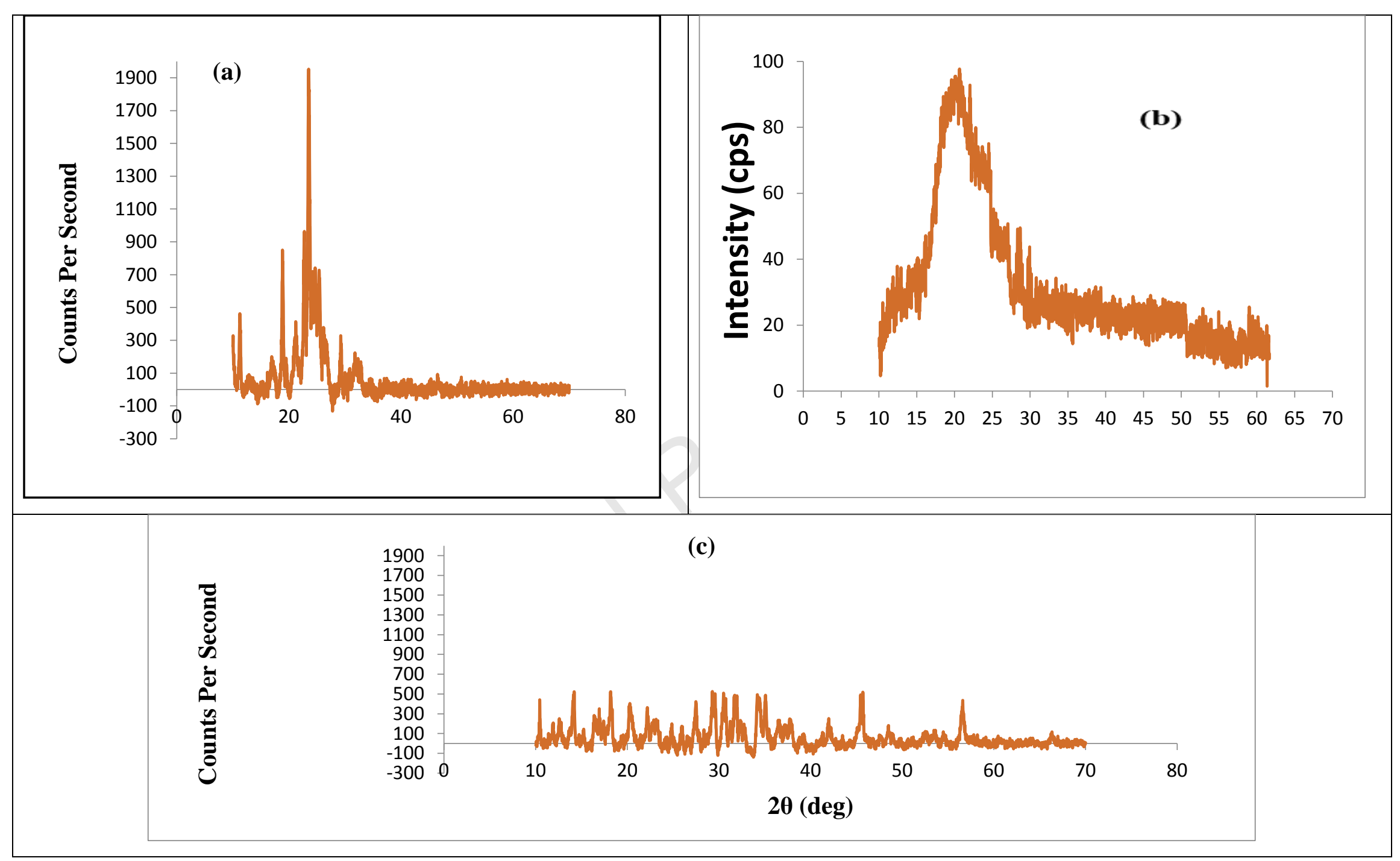

Fig. 9. 


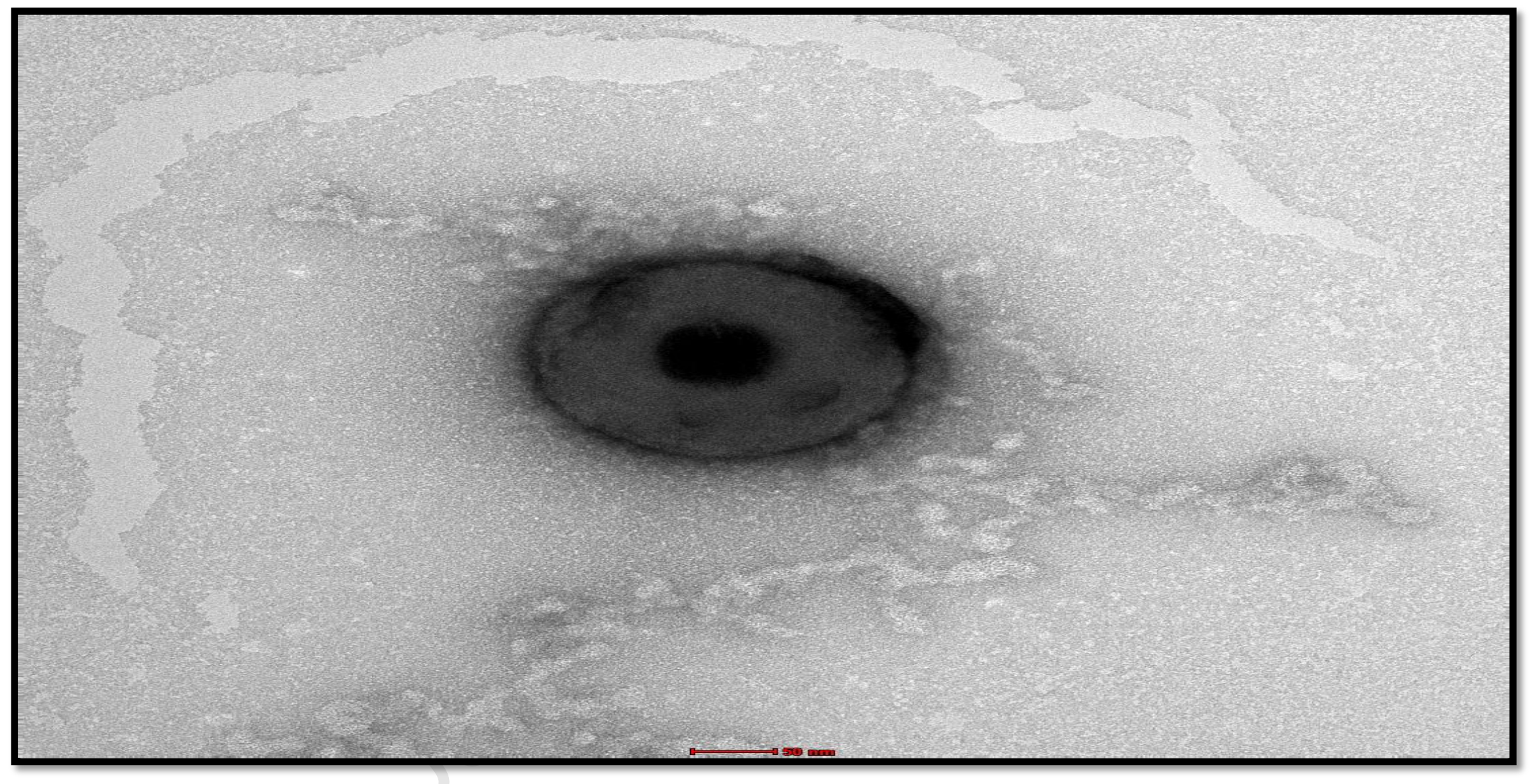

Fig. 10. 